\title{
Green supply chain game model and contract design: risk neutrality vs. risk aversion
}

\author{
Jianhu Cai ${ }^{1,2} \cdot$ Huazhen $\operatorname{Lin}^{1}\left[\right.$ D $\cdot$ Xiaoqing $\mathrm{Hu}^{2} \cdot$ Minyan Ping ${ }^{1}$
}

Received: 21 October 2021 / Accepted: 18 January 2022 / Published online: 7 March 2022

( $)$ The Author(s), under exclusive licence to Springer-Verlag GmbH Germany, part of Springer Nature 2022

\begin{abstract}
This paper incorporates the players' risk attitudes into a green supply chain (GSC) consisting of a supplier and a retailer. The supplier conducts production and determines the green level and wholesale price as a game leader; the retailer sells green products to consumers and determines the retail price as a follower. Equilibrium solutions are derived, and the influence of risk aversion on the GSC is examined. Our results show that, for the centralized GSC, risk aversion lowers the green level and the retail price, while for the decentralized GSC, risk aversion lowers the wholesale price and the retail price, but it may induce the supplier to increase the green level given a high-risk tolerance of the supplier. Meanwhile, the risk-averse decentralized GSC may obtain more expected profit than the risk-neutral decentralized GSC. Furthermore, this paper designs a revenue-and-cost-sharing joint contract to coordinate the risk-neutral GSC, and such a contract can improve the risk-averse GSC under specific conditions.
\end{abstract}

Keywords Green supply chain $\cdot$ Risk aversion $\cdot$ Revenue-and-cost-sharing joint contract $\cdot$ Pareto improvement

\section{Introduction}

With the advance of economy and sharp increase in energy consumption, more and more people begin to be concerned about environmental issues, such as greenhouse effects, marine pollution, ecological environment deterioration, and energy crises. Green production and clean energy have become global priorities for protecting the environment. Meanwhile, people's consciousness of environmental protection and health is increasing, and they are increasingly in favor of green consumption (Hong and Guo 2019; Bai et al. 2020; Li et al. 2021a; Wang et al. 2021). Then, the enterprises have the motivation to produce green products with consumers' green demand fed back from downstream retailers (Wang et al. 2021). In practice, Patagonia is a typical clothing company producing green products. When

Responsible Editor: Philippe Garrigues

Huazhen Lin

linzjut@163.com

1 School of Management, Zhejiang University of Technology, Hangzhou 310023, China

2 School of Management, Hangzhou Dianzi University, Hangzhou 310018, China producing the Eco Rain Shell Jacket, Patagonia collaborates with its suppliers to make efforts in material changes, finally substituting perfluorooctanoic acid with polyester and polyurethane to reduce polluting the environment. Meanwhile, Patagonia teams up with Centerstone Technologies to serve consumers more efficiently and increases inventory turns and, thus, revenues (Ghosh and Shah 2012). In China, many enterprises have begun to regard green development as their social responsibility and have started green production. For environmentally friendly considerations, China Baowu Steel Group Corporation, a leading manufacturer of steel products, has adopted the Baosteel Product Environmental Index (BPEI) to promote the development of green products. Baowu has achieved substantial growth in green products by reducing carbon emissions through Baosteel laminated steel and Baosteel quenching-partitioning steel. ${ }^{1}$ Another example is from the Haier Group, a leading brand of white goods business, which carries out the 4G strategy of "Green Product, Green Enterprise, Green Culture, and Green Recovery" to realize a harmonious relationship between humans and nature. They develop MagLev central air-conditioning, "no

\footnotetext{
${ }_{1}$ http://res.baowugroup.com/files/2019/11/27/628f2cf8866742c 2897796abc022230a.pdf
} 
external barrel" washing machines, and other green products with high efficiency and energy savings that are welcomed by consumers. ${ }^{2}$

Generally, the introduction of green products changes the competition structures and optimal decisions of a supply chain (SC). Many scholars have begun to study game models and cooperation mechanisms between suppliers and retailers in green supply chains (GSCs) (Hong and Guo 2019; Heydari et al. 2019; Li et al. 2021a, 2021b; Chen et al. 2021). Some scholars believe that enterprises may face greater risks in a GSC than those in a traditional SC and hence introduce risk attitudes into GSC management. For example, Zhao et al. (2020) construct a SC under carbon emission tax regulation and apply the conditional value-at-risk (CVaR) criteria to quantify the risk-averse attitude of the retailer. Then, both the risk-neutral supplier's optimal production quantity and the risk-averse retailer's optimal order quantity are investigated. Bai et al. (2020) adopt the mean-variance (MV) method and use utility profit to reflect the players' risk-averse attitudes and then develop two optimization models for manufacturer-led decentralized systems with and without technology investment. They mainly examine the impacts of sustainability investment and risk aversion on the SC coordination. Wang et al. (2021) also use the utility function to evaluate the riskaverse players' performance in a GSC and propose three contracts to improve the green level of products. From the above discussions, we can conclude that the players' risk aversion has raised many concerns in GSC management. Through this study, we want to stress the following questions:

(1) How do the players' risk-averse attitudes affect the GSC members' optimal decisions?

(2) How do the players' risk-averse attitudes affect the performance of the GSC?

(3) How can the revenue-and-cost-sharing (RCS) joint contract improve the performance of GSCs with risk neutrality and risk aversion?

To answer the above questions, a GSC with a risk-averse supplier and a risk-averse retailer is established. The supplier firstly makes decision on the green level and the wholesale price, and then the retailer determines the retail price. We apply the MV model to quantify the players' risk-averse attitudes and introduce the concept of risk tolerance to reflect the degree of the players' risk aversion. To clearly dig out the influence of players' risk-averse attitudes on the GSC, we develop a risk-neutral GSC as a basic model. The equilibrium solutions of a risk-neutral and a risk-averse GSC are derived and compared. Furthermore, the RCS joint contract

\footnotetext{
2 https://imagegroup1.haier.com/global/csr/W0202007216044639587 89.pdf?spm=net.32021\%20pc.hg2020\%20srdownload_20200908.3
}

is designed to improve the performance of GSCs with risk neutrality and risk aversion. In general, we obtain the following key findings.

a. When risk tolerance is valid, the equilibrium retail price and green level in the risk-averse centralized GSC are lower than those in the risk-neutral centralized GSC. Meanwhile, the equilibrium retail price and wholesale price in the risk-averse decentralized GSC are lower than those in the risk-neutral decentralized GSC, but this is not always true for the green level.

b. When risk tolerance is valid, the expected profit of the risk-averse centralized GSC is lower than that of the risk-neutral centralized GSC. However, the expected outcome is very different in the case of decentralized GSCs: when the supplier's risk tolerance is relatively high, the risk-averse supplier's optimal expected profit is higher than that of the risk-neutral supplier; and when the supplier's risk tolerance is relatively low but the retailer's risk tolerance is relatively high, the risk-averse retailer's optimal expected profit is higher than that of the risk-neutral retailer. Generally, the expected profit of the risk-averse decentralized GSC may be higher than that of the risk-neutral decentralized GSC.

c. When introducing the RCS joint contract, if the contract parameters satisfy certain conditions, the risk-neutral GSC and the risk-averse GSC are efficient in improving the performance. Meanwhile, the RSC joint contract can coordinate the risk-neutral GSC, and the coordinating profits can be flexibly allocated between the two members by adjusting the revenue-sharing ratio or the costsharing ratio. The RSC joint contract, however, cannot coordinate the risk-averse GSC; it can only improve both members' expected profits under specific conditions.

The rest of this paper is organized as follows. Literature review of GSC coordination and risk aversion is presented in "Literature review". "Model development" constructs the decision models of GSCs with risk neutrality and risk aversion. The optimal solutions and corresponding expected profits are obtained in different models. "Contract design" proposes the RCS contract with different schemes to improve the performance of GSCs. "Numerical examples" gives a numerical study to validate the propositions. "Conclusions and discussions" summarizes the conclusions. All proofs are shown in the appendix.

\section{Literature review}

In recent years, there have been many studies on GSCs. In general, two categories have attracted attention in GSC management: pricing and quantity tactics (Huang et al. 2016; 
Taleizadeh et al. 2018; Liu 2019; Qu et al. 2019; Li et al. 2021b) and cooperation and GSC coordination (Ghosh and Shah 2012, 2015; Swami and Shah 2013). Two streams of literature are bound up: GSC coordination and risk aversion. In the next, we mainly review these two streams and propose the research position of this study.

\section{GSC coordination}

GSC management has been the subject of much concern in recent decades. Many scholars consider that when green products are produced and sold to consumers, their demand function is different from that for nongreen products. Ghosh and Shah (2012) model the demand for green products as a linear function of the green level and retail price, which can reflect both "price-" and "green-" conscious consumer bases. They examine and compare the equilibrium solutions given different channel structures and investigate the impacts of channel structure on the optimal decisions. Finally, a twopart tariff contract is designed to improve the efficiency of the GSC. When enterprises make investments in $R \& D$ to improve the green level of products, advanced technologies are adopted to conduct green production processes, and they incur certain cost, which can be summarized as greening cost. (Ghosh and Shah 2012) or greenness cost (Liu et al. 2021). Swami and Shah (2013) find that the ratio of the optimal green efforts invested by the GSC members is equal to the ratio of their green sensitivity ratios and greening cost ratios. Ghosh and Shah (2015) study the coordination problem of a GSC and introduce two kinds of cost-sharing contracts: one is offered by the retailer, and the other is proposed through bargaining. The results show that the latter contract leads to a higher GSC surplus than the former contract. Basiri and Heydari (2017) consider the situation in which the SC sells both traditional nongreen products and new substitutable green products in the same channel and then proposes a collaboration strategy for the manufacturer and the retailer. The study reveals that the proposed collaboration model is capable of enhancing the SC profit fairly close to the centralized model and also ensures higher profits for both channel members. In addition to producing green products, reducing carbon emissions can also be seen as a key process in green production and can be considered in the category of GSC management. Xu et al. (2017) propose a GSC with one manufacturer and one retailer under cap-andtrade regulation; they focus on studying the production and emission abatement decisions of the GSC. Then, a wholesale price contract and a cost-sharing contract are designed to coordinate the GSC. Taleizadeh et al. (2018) introduce a two-echelon GSC selling a product with low-carbon emission and discuss the competition between one manufacturer and one retailer. In their study, three different contracts are designed to coordinate the GSC. Liu (2019) explores a GSC consisting of one retailer and one low-carbon manufacturer and proposes four different kinds of cost-sharing contracts to coordinate the GSC.

\section{Risk aversion}

Risk management has become increasingly important in today's complex SCs (Yang et al. 2021). More and more studies have emphasized the need to integrate risk management strategies into the company's decision-making process. For most SCs, they may face demand uncertainty or supply uncertainty in reality. Hence, the SC members pay much attention to risk management. Many scholars have studied the problem of risk management in SC. Xie et al. (2011) find that risk aversion significantly affects the SC's quality investment and pricing decisions. Xiao and Yang (2009) demonstrate that given a high-risk-sharing cost of the manufacturer, a high-risk-averse retailer chooses a higher wholesale price than a low-risk-averse retailer. Yang et al. (2018) reveal that, when the supplier is sufficiently more risk averse than the retailer, the optimal order quantity in the pull newsvendor model is lower than that in the push newsvendor model, and this result is the opposite to the risk-neutral SC.

To date, researchers have proposed various methods to model risk attitudes in decision-making problems, such as MV (Choi et al. 2008, 2019; Xu et al. 2014; Liu et al. 2016; Zhuo et al. 2018), value at risk (VaR) (Tapiero 2005; Wang et al. 2009; Kellner and Rösch 2016), CVaR (Li et al. 2016a; Zhu et al. 2020; Fan et al. 2020; Liu et al. 2020), and downside risk aversion (DRA) (Yao et al. 2016; Cai et al. 2019).

The MV formulation is a groundbreaking theory for portfolio risk management in finance Markowitz (1952). Markowitz's portfolio theory believes that investors expect the greatest return, but they are risk averse. Hence, the basis for investors to establish a portfolio is to maximize the return under a given risk level, and the given risk level is called risk tolerance. Over the recent past decades, Markowitz's MV framework has extended its influence from financial studies to SC studies (Chiu and Choi 2016). The core of portfolio research is to pursue the goal of maximizing returns by portfolios within the risk tolerance. Hence, for risk-averse decision-makers in SCs, they need to make decisions within their risk tolerance.

The MV model is widely adopted by researchers to study the optimal decisions and coordination mechanisms of a SC with risk-averse attitudes (Chiu and Choi 2016; Bai et al. 2020). To cite a few, Wei and Choi (2010) use the MV decision framework to measure the players' risk attitudes and introduce a wholesale pricing and profit-sharing scheme to coordinate the SC. Xu et al. (2014) establish a dual-channel SC and derive and compare the risk-averse members' optimal decisions under the MV model. Then, a two-way revenue-sharing contract is proposed to realize SC coordination. 
Table 1 Summary of some relevant literature

\begin{tabular}{|c|c|c|c|c|c|}
\hline Papers & SC structure & Type of contract & Green SC & Risk measure methods & Risk preference \\
\hline Bai et al. (2020) & $\begin{array}{l}\text { One manufacturer and } \\
\text { one retailer }\end{array}$ & $\begin{array}{l}\text { Revenue-sharing con- } \\
\text { tract; two-part tariff } \\
\text { contract }\end{array}$ & $\sqrt{ }$ & $\begin{array}{l}\text { Utility function based } \\
\text { on MV }\end{array}$ & $\begin{array}{l}\text { Risk-averse manufacturer } \\
\text { and risk-averse retailer }\end{array}$ \\
\hline Cai et al. (2019) & $\begin{array}{l}\text { One supplier and one } \\
\text { buyer }\end{array}$ & $\begin{array}{l}\text { Revenue-sharing con- } \\
\text { tract }\end{array}$ & - & DRA & $\begin{array}{l}\text { Risk-averse supplier and } \\
\text { risk-averse buyer }\end{array}$ \\
\hline Fan et al. (2020) & $\begin{array}{l}\text { One supplier and one } \\
\text { buyer }\end{array}$ & Option contract & - & CVaR & $\begin{array}{l}\text { Risk-averse supplier and } \\
\text { risk-averse buyer }\end{array}$ \\
\hline Ghosh and Shah (2015) & $\begin{array}{l}\text { One manufacturer and } \\
\text { one retailer }\end{array}$ & $\begin{array}{l}\text { Cost-sharing contract; } \\
\text { bargaining cost-sharing } \\
\text { contract }\end{array}$ & $\sqrt{ }$ & - & $\begin{array}{l}\text { Risk-neutral manufacturer } \\
\text { and risk-neutral retailer }\end{array}$ \\
\hline Li et al. (2016a) & $\begin{array}{l}\text { One supplier and one } \\
\text { retailer }\end{array}$ & Rik-sharing contract & - & CVaR & $\begin{array}{l}\text { Risk-neutral supplier and } \\
\text { risk-averse retailer }\end{array}$ \\
\hline Liu et al. (2020) & $\begin{array}{l}\text { One supplier and one } \\
\text { retailer }\end{array}$ & Option contract & - & CVaR & $\begin{array}{l}\text { Risk-neutral supplier and } \\
\text { risk-averse retailer }\end{array}$ \\
\hline Wang et al. (2021) & $\begin{array}{l}\text { One supplier and one } \\
\text { retailer }\end{array}$ & $\begin{array}{l}\text { Wholesale price con- } \\
\text { tract; reward contract } \\
\text { without target green } \\
\text { degree; reward con- } \\
\text { tract with target green } \\
\text { degree }\end{array}$ & $\sqrt{ }$ & $\begin{array}{l}\text { Utility function based } \\
\text { on MV }\end{array}$ & $\begin{array}{l}\text { Risk-averse supplier and } \\
\text { risk-averse retailer }\end{array}$ \\
\hline Yao et al. (2016) & $\begin{array}{l}\text { One supplier and one } \\
\text { retailer }\end{array}$ & $\begin{array}{l}\text { Price-only contract; } \\
\text { returns policies con- } \\
\text { tract; revenue-sharing } \\
\text { contract }\end{array}$ & - & DRA & $\begin{array}{l}\text { Risk-neutral supplier and } \\
\text { risk-averse retailer }\end{array}$ \\
\hline Zhao et al. (2020) & $\begin{array}{l}\text { One supplier and one } \\
\text { retailer }\end{array}$ & Call option contract & $\sqrt{ }$ & CVaR & $\begin{array}{l}\text { Risk-neutral supplier and } \\
\text { risk-averse retailer }\end{array}$ \\
\hline Zhu et al. (2020) & $\begin{array}{l}\text { One manufacturer and } \\
\text { one retailer }\end{array}$ & $\begin{array}{l}\text { A joint contract consist- } \\
\text { ing of a revenue- } \\
\text { sharing contract and } \\
\text { an improved buyback } \\
\text { contract }\end{array}$ & - & CVaR & $\begin{array}{l}\text { Risk-neutral manufacturer } \\
\text { and risk-averse retailer }\end{array}$ \\
\hline Zhuo et al. (2018) & $\begin{array}{l}\text { One supplier and one } \\
\text { retailer }\end{array}$ & Option contract & - & MV & $\begin{array}{l}\text { Risk-averse supplier and } \\
\text { risk-averse retailer }\end{array}$ \\
\hline This paper & $\begin{array}{l}\text { One supplier and one } \\
\text { retailer }\end{array}$ & $\begin{array}{l}\text { Revenue-and-cost- } \\
\text { sharing (RCS) joint } \\
\text { contract }\end{array}$ & $\sqrt{ }$ & MV & $\begin{array}{l}\text { Risk-averse supplier and } \\
\text { risk-averse retailer }\end{array}$ \\
\hline
\end{tabular}

Zhuo et al. (2018) use the MV method to model the SC members' risk-averse attitudes and find that under an option contract, a relatively high-risk tolerance can induce the supplier to decrease the exercise price. Bai et al. (2020) use utility profits to evaluate the players' performance based on the MV framework and then study the effect of sustainability investment on the GSC. Wang et al. (2021) also adopt the MV approach and present a utility function to measure the members' risk attitudes and then analyze the members' optimal decisions about the green level and the retail price in a GSC. In this study, we also consider a GSC with a supplier producing green products, and we employ the MV approach to model the members' risk-averse attitudes. Moreover, the risk tolerance is adopted in the GSC to reflect the degrees of the members' risk aversion.

Under the MV formulation, two methods are often used to build risk management models. The first method is to maximize the expected profit under the constraint of random profit variance (Xie et al. 2011; Xu et al. 2014; Liu et al. 2016; Zhuo et al. 2018; Raza and Govindaluri 2019). The second method is to maximize utility function under the MV framework (Bai et al. 2020; Wang et al. 2021). In the newsvendor setting, the first method has very nice features and physical meanings. The first method is better than the second method in the sense that the solution is well-bounded and there won't be problem associated with negative "utility" as can be found in the second method (Chiu and Choi 2016).

\section{The distinctiveness of this research}

Table 1 makes a clear comparison between this paper and most related literature to posit the contributions. We develop a GSC with a risk-averse supplier producing green products and selling the products through a risk-averse retailer. The 
impact of risk aversion on the GSC is examined by deriving and comparing the optimal decisions of the GSCs with risk neutrality and risk aversion. Most related works can be found in Bai et al. (2020) and Zhao et al. (2020). Bai et al. (2020) employ the MV approach to develop a manufacturerled GSC with technology investment in green products. The members' optimal decisions are derived by maximizing their utility profits. Then, they design a two-part tariff contract to realize GSC coordination. Zhao et al. (2020) consider a SC under carbon emission tax regulation. The retailer is risk averse, and the CVaR method is adopted to quantify the riskaverse attitude. Then, they propose a call option contract to improve both members' profits. Different from their works, we adopt the MV method in which a parameter of risk tolerance is applied to measure the members' risk aversion. Meanwhile, we develop a risk-neutral GSC as a basic model and compare the optimal decisions of a risk-neutral and a risk-averse GSC. Thus, the influence of risk aversion on the GSC is investigated. Furthermore, joint RCS contracts are proposed to improve the GSCs with risk neutrality and risk aversion. Generally speaking, the main contributions of our study can be summarized in the following.

(1) We introduce the MV method to reflect the GSC members' risk aversion from a new perspective in which the concept of risk tolerance is adopted. Such a research perspective combines the goal of maximizing the expected profits and the consideration of avoiding high risks of the members together. Thus, our results can help enterprises make optimal decisions according to the risk tolerances.

(2) We contribute to the literature on improving the GSC performance by designing the RCS joint contract. The contract scheme can be easily applied in practice to strengthen the cooperation between the members in a risk-averse GSC.

(3) We identify the key characteristics of risk-neutral GSCs through comparison analysis between risk-neutral GSCs and risk-averse GSCs. The key findings can help enterprises be aware of the impacts of risk aversion on GSCs and can be applied in practice to support the enterprises' decisions.

\section{Model development}

We establish a GSC consisting of a supplier ("he") and a retailer ("she"). The retailer purchases green products from the supplier and sells the products to consumers. We assume the unit production cost is $c$, the wholesale price is $w$, and the retail price is $p$.The demand function can be expressed
Table 2 Main notations

\begin{tabular}{ll}
\hline & Description \\
\hline Notation & \\
$x$ & Random market demand \\
$u$ & The mean value of random market demand \\
$\delta$ & The standard variance of random market demand \\
$c, c_{g}$ & Unit production cost, greening cost \\
$p$ & Retail price \\
$w$ & Wholesale price \\
$q$ & Order quantity \\
$\theta$ & Green level \\
$\lambda$ & Revenue-sharing ratio \\
$\phi$ & Cost-sharing ratio \\
$\eta$ & Greening effort cost coefficient \\
$b, g$ & Retail price elastic coefficient and green elastic coef- \\
& ficient \\
$R_{t}, R_{s}, R_{r}$ & Risk tolerances of the GSC, the supplier, and the retailer \\
$\pi$ & Profit \\
Subscript & \\
$r$ & Retailer \\
$s$ & Supplier \\
$t$ & The GSC \\
Superscript & \\
$d$ & Decentralized GSC \\
$s$ & Revenue-and-cost-sharing contract \\
$R$ & Risk-averse GSC \\
\hline & Optimal solution \\
\hline &
\end{tabular}

as $q=x-b p+g \theta$, where $x$ is a stochastic variable denoting the market potential with mean value $u$ and variance $\delta^{2}, b$ denotes the retail price sensitivity, $\theta$ is the green level, and $g$ denotes the market greening responsiveness. Then, a higher green level and a lower retail price can help expand the demand for products. To reflect the supplier's cost for R\&D investment in green production, many scholars assume the greening cost as a quadratic function of the green level $(\mathrm{Li}$ et al. 2016b; Zhu and He 2017; Song and Gao 2018). In this paper, we utilize the greening cost function as $c_{g}=\frac{1}{2} \eta \theta^{2}$, which is independent of the production quantity. Here, $\eta>0$ denotes the greening effort cost efficiency.

In this paper, we assume that both members are risk averse, adopt the MV model, and introduce a parameter $R$ $(R>0)$ to represent the risk tolerance of the decision-maker. Here, a higher $R$ indicates a higher risk tolerance, which means that the decision-maker is less afraid of uncertainty and is more adventurous. Then, $R=\infty$ means that the decision-maker is totally risk neutral; $R=0$ indicates that the decision-maker is completely risk averse. Table 2 lists the main notations employed in the paper.

To simplify our analysis without loss of generality, we further assume that (i) $p>w$ and $w>c>0$, which ensure 
that each member can make a positive profit; (ii) $b>g$ and $\eta>g$, which suggest that consumers are more sensitive to the retail price than to the green level, and then the supplier needs to make substantial investments to obtain a certain green level; (iii) $R_{t}=R_{s}+R_{r}$, which demonstrates that the GSC's risk tolerance equals to the summation of the supplier's risk tolerance and retailer's risk tolerance; and (iv) $q=u-b c>0$, which ensures that the market demand for nongreen products is positive.

\section{Centralized GSC}

In this section, we mainly investigate the centralized GSC in which the supplier and the retailer make decisions as a union to optimize performance of the whole GSC. Let $\pi_{t}$ denote the GSC's stochastic profit. For the risk-neutral centralized GSC, it aims to maximize the expected profit in the following.

$E\left(\pi_{t}\right)=(p-c)(u-b p+g \theta)-\frac{1}{2} \eta \theta^{2}$

Then, the risk-averse centralized GSC needs to maximize the expected profit with the constraint of the standard variance of the stochastic profit.

$\max E\left(\pi_{t}\right)$

s.t. $\sqrt{\operatorname{Var}\left(\pi_{t}\right)} \leq R_{t}$

Here, $R_{t} \geq 0$ is the risk tolerance of the centralized GSC. A higher $R_{t}$ implies that the risk tolerance of the GSC tends to be higher, and the GSC is less risk averse. $\operatorname{Var}\left(\pi_{t}\right)$ is the variance of the centralized GSC's stochastic profit, which can be expressed as follows:

$\operatorname{Var}\left(\pi_{t}\right)=E\left[\pi_{t}-E\left(\pi_{t}\right)\right]^{2}=(p-c)^{2} \delta^{2}$

By analyzing the decision models of the centralized GSCs with risk neutrality and risk aversion, we obtain Proposition 1.

Proposition 1. When the centralized GSC is risk neutral, the optimal retail price and green level are $p_{t}^{*}=\frac{(u-b c) \eta}{2 b \eta-g^{2}}+c$ and $\theta_{t}^{*}=\frac{(u-b c) g}{2 b \eta-g^{2}}$; when the centralized GSC is risk averse, if $R_{t}<R^{\prime}$, the optimal retail price and green level are $p_{t}^{R *}=\frac{R_{t}}{\delta}+c$ and $\theta_{t}^{R *}=\frac{g R_{t}}{\delta \eta}$; here $R^{\prime}=\frac{(u-b c) \delta \eta}{2 b \eta-g^{2}}$.

Proposition 1 demonstrates that a unique equilibrium solution exists when the centralized GSC is risk neutral. On the other hand, for the risk-averse centralized GSC, when the risk tolerance $R_{t}$ is relatively low, i.e., $R_{t}<R^{\prime}$, Constraint (2) is valid; there also exists a unique equilibrium solution. It is evident that the risk-averse GSC's optimal green level and retail price are smaller than those of the risk-neutral GSC; when the risk tolerance $R_{t}$ is relatively high, i.e., $R_{t} \geq R^{\prime}$, Constraint (2) becomes invalid, and the risk-averse GSC's problem becomes the risk-neutral GSC's problem. In the rest of the paper, we only consider the situation when the constraint is valid, i.e., risk tolerance is valid. From Proposition 1, we can further deduce the conclusions presented in Corollary 1.

Corollary $1(a)$ For the risk-neutral centralized GSC, both $p_{t}^{*}$ and $\theta_{t}^{*}$ increase with $u$ and $g$, decrease with $b$ and $\eta$, and are independent of $\delta$; for the risk-averse centralized GSC, both $p_{t}^{R *}$ and $\theta_{t}^{R *}$ increase with $R_{t}$, decrease with $\delta$, and are independent of $u$ and $b$; meanwhile, $p_{t}^{R *}$ is independent of $g$ and $\eta$, and $\theta_{t}^{R *}$ increases with $g$ and decreases with $\eta$. (b) The risk-tolerance threshold $R^{\prime}$ increases with $u, g$, and $\delta$ and decreases with $b$.

According to Corollary $1(a)$, the risk-neutral centralized GSC is concentrated on $u, g, b$, and $\eta$ when choosing its optimal retail price and green level. The impacts of the increases of $u$ and $g$ are positive, and the impacts of the increases of $b$ and $\eta$ are negative. Since the risk-neutral centralized GSC focuses on maximizing its expected profit, the standard deviation cannot influence its optimal decisions; however, for the risk-averse centralized GSC, both optimal retail price and green level are independent of $u$ and $b$. It is mainly concentrated on $R_{t}$ and $\delta$ : The impact of the increase of $R_{t}$ is positive, and the impact of the increase of $\delta$ is negative. The interesting result is that the optimal retail price is independent of $g$, and the optimal green level increases with $g$. The main reason is that the optimal green level doesn't directly influence the standard deviation of the stochastic profit. Then the increase of $g$ intuitively improves the optimal green level even when the centralized GSC is risk averse. Similar management insights also can be used to explain why the optimal retail price is independent of $\eta$ and the optimal green level decreases with $\eta$.

Corollary $1(b)$ shows that, with the increases of $u, g$, and $\delta$, the risk-averse centralized GSC will face the increase of the risk-tolerance threshold $R^{\prime}$. A relatively high $R^{\prime}$ means that the risk-averse centralized GSC is more sensitive to risks since $R_{t}<R^{\prime}$ more easily holds. On the contrary, with the increases of $b$, the risk-averse centralized GSC will face the decrease of the risk-tolerance threshold $R^{\prime}$. A relatively low $R^{\prime}$ means that the risk-averse centralized GSC is less sensitive to risks since $R_{t}<R^{\prime}$ more difficultly holds.

Corollary 2. Comparing the risk-neutral centralized GSC with the risk-averse centralized GSC, we can obtain $p_{t}^{R *}<p_{t}^{*}, \theta_{t}^{R *}<\theta_{t}^{*}$, and $E\left(\pi_{t}^{R *}\right)<E\left(\pi_{t}^{*}\right)$.

Corollary 2 concludes that when risk tolerance is valid, the risk-averse centralized GSC chooses a lower green level than the risk-neutral GSC, as well as the retail price. Correspondingly, the risk-averse centralized GSC obtains a lower expected profit than the risk-neutral centralized GSC. It indicates that risk aversion makes the centralized GSC more cautious when making decisions, and thus, the expected profit of the GSC is decreased. 


\section{Decentralized GSC}

In a decentralized GSC, both the GSC members make decisions from the perspective of their own benefits. For the risk-neutral decentralized GSC, all members seek to maximize their expected profits. Here, the risk-neutral retailer's expected profit can be written as follows:

$E\left(\pi_{r}^{d}\right)=(p-w)(u-b p+g \theta)$

Then, the risk-averse retailer needs to maximize the expected profit with the constraint of the standard variance of the stochastic profit.

$\max E\left(\pi_{r}^{d}\right)$

s.t. $\sqrt{\operatorname{Var}\left(\pi_{r}^{d}\right)} \leq R_{r}$

Here, $R_{r} \geq 0$ denotes the retailer's risk tolerance. A higher $R_{r}$ indicates that the retailer is less risk averse. $\operatorname{Var}\left(\pi_{r}^{d}\right)$ is the variance of the retailer's stochastic profit, which can be given as follows:

$\operatorname{Var}\left(\pi_{r}^{d}\right)=E\left[\pi_{r}^{d}-E\left(\pi_{r}^{d}\right)\right]^{2}=(p-w)^{2} \delta^{2}$

Similarly, a risk-neutral supplier's expected profit can be expressed as follows:

$E\left(\pi_{s}^{d}\right)=(w-c)(u-b p+g \theta)-\frac{1}{2} \eta \theta^{2}$

Then, the risk-averse supplier needs to maximize the expected profit with the constraint of the standard variance of the stochastic profit.

$\max E\left(\pi_{s}^{d}\right)$

s.t. $\sqrt{\operatorname{Var}\left(\pi_{s}^{d}\right)} \leq R_{s}$

Here, $R_{s} \geq 0$ is the risk tolerance of the supplier. A higher $R_{s}$ implies that the supplier is less risk averse. $\operatorname{Var}\left(\pi_{s}^{d}\right)$ is the variance of the supplier's stochastic profit, which can be given by the following:

$\operatorname{Var}\left(\pi_{s}^{d}\right)=E\left[\pi_{s}^{d}-E\left(\pi_{s}^{d}\right)\right]^{2}=(w-c)^{2} \delta^{2}$

Using backward induction, we can obtain the members' optimal decisions in GSCs with risk neutrality and risk aversion, as shown in Proposition 2.

Proposition 2. When the GSC members are risk neutral, the optimal wholesale price, green level, and retail price are given by $w^{d *}=\frac{2(u-b c) \eta}{4 b \eta-g^{2}}+c, \quad \theta^{d *}=\frac{(u-b c) g}{4 b \eta-g^{2}}$, and $p^{d *}=$ $\frac{3(u-b c) \eta}{4 b \eta-g^{2}}+c$; when the GSC members are risk averse, if

$R_{s}<R_{s}^{d^{\prime}}$ and $R_{r}<R_{r}^{d^{\prime}}$ hold together, the optimal wholesale price, green level, and retail price are given by $w^{d R *}=\frac{R_{s}}{\delta}+c$,

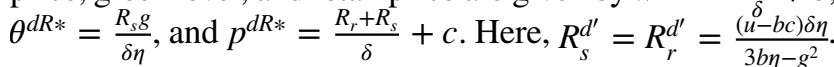

Proposition 2 demonstrates that a unique equilibrium exists in the risk-neutral decentralized GSC. For the riskaverse decentralized GSC, there also exists a unique equilibrium when the risk constraints are valid. By analyzing the optimal decisions in different decentralized GSCs with risk neutrality and risk aversion, we can further deduce the following corollary.

Corollary 3. (a) For the risk-neutral decentralized GSC, $p^{d *}, \theta^{d *}$, and $w^{d *}$ increase with $u$ and $g$, decrease with $b$, and are independent of $\delta$; for the risk-averse decentralized GSC, $p^{d R *}, \theta^{d R *}$, and $w^{d R *}$ increase with $R_{s}$, decrease with $\delta$, and are independent of $u ; \theta^{d R *}$ increases with $g ; p^{d R *}$ increases with $R_{r}$; and $(b) R_{s}^{d^{\prime}}$ and $R_{r}^{d^{\prime}}$ increase with $u, g$ and $\delta$ but decrease with $b$.

Corollary $3(a)$ can be illustrated as follows. For the risk-neutral decentralized GSC, a high mean value of the market potential indicates an optimistic market demand, and a high green elastic coefficient means a high consumers' sensitiveness to the green level. Then, the supplier tends to increase the green level and wholesale price, which induces the retailer to choose a higher retail price. Meanwhile, the risk-neutral GSC members' decisions are not influenced by the standard variance of the market potential.

Different from the risk-neutral GSC, the risk-averse GSC members' optimal decisions are not influenced by the mean value of the market potential, but they are affected by the standard variance of the market potential and the members' risk tolerances. This is because risk-averse members are more concerned about the fluctuation of market demand, and thus, their decisions are deeply related to risk tolerance. Especially, we find that an increase in the supplier's risk tolerance can increase all values of equilibrium decisions, while the impacts from the standard deviation of the market potential are opposite. Furthermore, the equilibrium green level is increasing in the green elastic coefficient, and the equilibrium retail price is increasing in the retailer's risk tolerance.

From Corollary $3(b)$, we can also conclude that with the increase of $u, g$, and $\delta$, both the supplier and the retailer become less sensitive to risks, while with the increase of $b$, the two members become more sensitive to risks. This conclusion is consistent with that in the centralized GSC.

To focus on discussing the decision differences between the decentralized GSCs with different risk attitudes, we can further deduce Corollary 4 as follows.

Corollary 4. When $R_{s}<R_{s}^{d^{\prime}}$ and $R_{r}<R_{r}^{d^{\prime}}$, there exist (a) $p^{d R *}<p^{d *}$ and $w^{d R *}<w^{d *} ;(b)$ if $0<R_{s}<\frac{(u-b c) \delta \eta}{4 b \eta-g^{2}}$, then 
$\theta^{d R *}<\theta^{d *}$; if $\frac{(u-b c) \delta \eta}{4 b \eta-g^{2}} \leq R_{s}<R_{s}^{d^{\prime}}$, then $\theta^{d R *} \geq \theta^{d *} ;$ (c) if $0<R_{r}<R_{r}^{d t}$, then $E\left(\pi_{r}^{d *}\right)>E\left(\pi_{r}^{d R *}\right)$; if $R_{r}^{d t} \leq R_{r}<R_{r}^{d^{\prime}}$, then $E\left(\pi_{r}^{d *}\right) \leq E\left(\pi_{r}^{d R *}\right) ;(d)$ if $0<R_{r}<\frac{(u-b c) \delta}{b}\left(1-\sqrt{\frac{2 b \eta-g^{2}}{4 b \eta-g^{2}}}\right)$ and $0<R_{s}<R_{s}^{d t}$ hold together, or $\frac{(u-b c) \delta}{b}$ $\left(1-\sqrt{\frac{2 b \eta-g^{2}}{4 b \eta-g^{2}}}\right)<R_{r}<R_{r}^{d^{\prime}}$ holds, then $E\left(\pi_{s}^{d *}\right)>E\left(\pi_{s}^{d R *}\right) ;$ and if $0<R_{r} \leq \frac{(u-b c) \delta}{b}\left(1-\sqrt{\frac{2 b \eta-g^{2}}{4 b \eta-g^{2}}}\right)$ and $R_{s}^{d t} \leq R_{s}<R_{s}^{d^{\prime}}$ hold together, then $E\left(\pi_{s}^{d *}\right) \leq E\left(\pi_{s}^{d R *}\right)$.

Here, $R_{r}^{d t}=\frac{(u-b c) \delta \eta-\left(b \eta-g^{2}\right) R_{s}}{2 b \eta}-\sqrt{\left(\frac{(u-b c) \delta \eta-\left(b \eta-g^{2}\right) R_{s}}{2 b \eta}\right)^{2}-\frac{(u-b c)^{2} \delta \eta^{2}}{\left(4 b \eta-g^{2}\right)^{2}}}$, and $R_{s}^{d t}=\frac{\eta}{2 b n-g^{2}}\left\{(u-b c) \delta-b R_{r}-\sqrt{\left((u-b c) \delta-b R_{r}\right)^{2}-\frac{(u-b c)^{2} \delta^{2}\left(2 b \eta-g^{2}\right)}{4 b \eta-g^{2}}}\right\}$.

Corollary $4(a)$ shows when risk tolerance is valid, the risk-averse decentralized GSC's optimal retail price and wholesale price are lower than those of the risk-neutral decentralized GSC. That is because both the GSC members are more cautious in making decisions when they are risk averse. By decreasing the optimal retail price and green level, the GSC members can control their risks according to their risk tolerances.

Corollary $4(b)$ indicates that the relative sizes of the risk neutral supplier's optimal green level and the riskaverse supplier's optimal green level depend on the value of $R_{s}$. If the risk-averse supplier's risk tolerance is relatively high, i.e., $\frac{(u-b c) \delta \eta}{4 b \eta-g^{2}} \leq R_{s}<R_{s}^{d^{\prime}}$, he is inclined to select a green level higher than that of the risk-neutral supplier. However, if the risk-averse supplier's risk tolerance is relatively low, i.e., $0<R_{s}<\frac{(u-b c) \delta \eta}{4 b \eta-g^{2}}$, he is inclined to choose a green level lower than that of the risk-neutral supplier. Hence, a relatively high-risk tolerance, i.e., $\frac{(u-b c) \delta \eta}{4 b \eta-g^{2}} \leq R_{s}<R_{s}^{d^{\prime}}$, can induce the risk-averse supplier to choose a relatively high service level, which benefits the consumers.

Corollary $4(c)$ means that the relative sizes of the risk-neutral retailer's optimal expected profit and the risk-averse supplier's optimal expected profit depend on the risk-averse retailer's risk tolerance. A relatively high-risk tolerance, i.e., $R_{r}^{d t} \leq R_{r}<R_{r}^{d^{\prime}}$, benefits the risk-averse retailer. On the contrary, a relatively lowrisk tolerance, i.e., $0<R_{r}<R_{r}^{d t}$, damages the risk-averse retailer.

According to Corollary $4(d)$, if the risk-averse retailer's risk tolerance is relatively high, i.e., $\frac{(u-b c) \delta}{b}$ $\left(1-\sqrt{\frac{2 b \eta-g^{2}}{4 b \eta-g^{2}}}\right)<R_{r}<R_{r}^{d^{\prime}}$, the risk-averse supplier's expected profit is lower than that of the risk-neutral supplier. However, if the risk-averse retailer's risk tolerance is relatively low, i.e., $0<R_{r}<\frac{(u-b c) \delta}{b}\left(1-\sqrt{\frac{2 b \eta-g^{2}}{4 b \eta-g^{2}}}\right)$, the riskaverse supplier's expected profit is higher than that of the risk-neutral supplier if and only if his risk tolerance is relatively high, i.e., $R_{s}^{d t} \leq R_{s}<R_{s}^{d^{\prime}}$.

Corollary 5. If $0<R_{r}<R_{r}^{d h}$ and $0<R_{s}<R_{s}^{d h}$ hold together, then $E\left(\pi_{t}^{d *}\right)>E\left(\pi_{t}^{d R *}\right)$; if $0<R_{r}<R_{r}^{d h}$ and $R_{s}^{d h} \leq R_{s}<R_{s}^{d^{\prime}}$ hold together, or $R_{r}^{d h} \leq R_{r}<R_{r}^{d^{\prime}}$ holds, then $E\left(\pi_{+}^{d *}\right) \leq E\left(\pi_{t}^{d R *}\right)$. $\mathrm{H} \quad \mathrm{e} \quad \mathrm{r} \quad \mathrm{e} \quad, \quad R_{r}^{d h}=\frac{(u-b c) \delta \eta\left[\left(4 b \eta-g^{2}\right)-\sqrt{\left(2 b \eta-g^{2}\right)\left(5 b \eta-g^{2}\right)}\right]}{2 b \eta\left(4 b \eta-g^{2}\right)} ;$ $R_{s}^{d h}=\frac{(u-b c) \delta \eta-\left(2 b \eta-g^{2}\right) R_{r}}{2 b \eta-g^{2}}-\frac{\sqrt{\frac{4(u-b c)^{2}(b \eta)^{2} \delta^{2} \eta^{2}}{\left(4 b \eta-g^{2}\right)^{2}}-g^{2}\left(2 b \eta-g^{2}\right)\left(R_{r}\right)^{2}}}{2 b \eta-g^{2}}$.

Corollary 5 shows that, if the risk-averse retailer's risk tolerance is relatively high, i.e., $R_{r}^{d h} \leq R_{r}<R_{r}^{d^{\prime}}$, the total expected profit of the risk-averse decentralized GSC is higher than that of the risk-neutral decentralized GSC. However, if the risk-averse retailer's risk tolerance is relatively low, i.e., $0<R_{r}<R_{r}^{d h}$, the total expected profit of the riskaverse decentralized GSC is higher than that of the riskneutral decentralized GSC if and only if the risk-averse supplier's risk tolerance is relatively high, i.e., $R_{s}^{d h} \leq R_{s}<R_{s}^{d^{\prime}}$.

Furthermore, we compare the results in Proposition 1 and Proposition 2 and then summarize the conclusions in Corollary 6 as follows.

Corollary 6. When $R_{t}<R^{\prime}, R_{s}<R_{s}^{d^{\prime}}$, and $R_{r}<R_{r}^{d^{\prime}}$, there exist (a) $\theta^{d *}<\theta_{t}^{*}$ and $\theta^{d R^{*}}<\theta_{t}^{R *} ;(b) p_{t}^{*}<p^{d *}$ and $p_{t}^{R *}=p^{d R *} ;(c) E\left(\pi_{t}^{d *}\right)<E\left(\pi_{t}^{*}\right)$ and $E\left(\pi_{t}^{d R *}\right)<E\left(\pi_{t}^{R *}\right)$; and (d) $R^{d^{\prime}}>R^{\prime}$, where $R^{d^{\prime}}=R_{r}^{d^{\prime}}+R_{s}^{d^{\prime}}$.

Corollary 6 reveals that $(i)$ no matter risk attitudes are introduced or not, the centralized GSC's optimal green level is higher than that of the decentralized GSC, and the centralized GSC obtains a higher expected profit compared with the decentralized GSC. Compared with the centralized GSC, the supplier always sets a lower green level, and the double marginalization effect is obvious in the decentralized GSC; (ii) if no risk attitude is introduced, the centralized GSC's optimal retail price is lower than that of the decentralized GSC. If risk attitudes are introduced, the centralized GSC's optimal retail price is equal to that of the decentralized GSC. Such result reveals that integration can induce the riskneutral GSC and set a lower retail price to expand market, but the risk-averse centralized GSC still keeps the same retail price as the risk-averse decentralized GSC so as to control risks; (iii) Corollary $6(d)$ reveals a special relationship between $R^{d^{\prime}}$ and $R^{\prime}$, i.e., $R_{r}^{d^{\prime}}+R_{s}^{d^{\prime}}>R^{\prime}$. Such relationship shows that, compared with the risk-averse decentralized GSC, risk-averse centralized GSC faces a relatively low total risk-tolerance threshold. Such result partly means integration may help GSC strengthens the capability to face risks. 


\section{Contract design}

Now, we introduce an RCS joint contract consisting of a revenue-sharing ratio and a cost-sharing ratio to improve the performance of the GSC. Such a contract scheme is applied in many industries, like the chemical, apparel, and pharmaceutical industries. For example, in the pharmaceutical industry, Fosun Pharma and BioNTech have reached an agreement on the mRNA Covid-19 vaccine BNT162. Fosun Pharma bears a certain ratio of $R \& D$ costs and shares a certain proportion of sales revenue, thus improving the performance of the SC. In this section, we adopt such a contract to improve the efficiency of GSCs with risk neutrality and risk aversion, respectively. In the RCS joint contract, $\lambda$ denotes the revenue-sharing ratio, and $\phi$ is the cost-sharing ratio. Then, the retailer shares the faction $\lambda$ of the sales revenue, and the supplier shares the remaining fraction $1-\lambda$. Meanwhile, the retailer bears the fraction $\phi$ of the greening cost, and the supplier bears the remaining fraction $1-\phi$. When $\lambda=1$ and $\phi=0$, the RCS joint contract is reduced to a simple wholesale price contract like that in the decentralized GSC, and no revenue or greening cost is shared between two members. When $\lambda=0$ and $\phi=1$, neither the retailer nor the supplier will accept the contract. Here, we assume $0<\lambda<1$ and $0<\phi<1$ hereafter in this paper.

According to the above discussions, the risk-neutral retailer's expected profit is as follows:

$E\left(\pi_{r}^{s}\right)=(\lambda p-w)(u-b p+g \theta)-\frac{1}{2} \phi \eta \theta^{2}$

Then, the risk-averse retailer needs to maximize the expected profit under the constraint of the stochastic profit standard deviation.

$\max E\left(\pi_{r}^{s}\right)$

s.t. $\sqrt{\operatorname{Var}\left(\pi_{r}^{s}\right)} \leq R_{r}$

$\operatorname{Var}\left(\pi_{r}^{s}\right)$ is the variance of the retailer's stochastic profit, which can be given by the following:

$\operatorname{Var}\left(\pi_{r}^{s}\right)=E\left[\pi_{r}^{s}-E\left(\pi_{r}^{s}\right)\right]^{2}=(\lambda p-w)^{2} \delta^{2}$

The risk-neutral supplier's expected profit can be expressed as follows:

$E\left(\pi_{s}^{s}\right)=[(1-\lambda) p+w-c](u-b p+g \theta)-\frac{1}{2}(1-\phi) \eta \theta^{2}$

Then, the risk-averse supplier needs to maximize the expected profit under the constraint of the stochastic profit standard deviation. $\max E\left(\pi_{s}^{s}\right)$

s.t. $\sqrt{\operatorname{Var}\left(\pi_{s}^{s}\right)} \leq R_{s}$

$\operatorname{Var}\left(\pi_{s}^{s}\right)$ is the variance of the supplier's stochastic profit, which can be given by the following:

$\operatorname{Var}\left(\pi_{s}^{s}\right)=E\left[\pi_{s}^{s}-E\left(\pi_{s}^{s}\right)\right]^{2}=[(1-\lambda) p+w-c]^{2} \delta^{2}$

Using backward induction, we first derive the optimal decisions of the GSCs with risk neutrality and risk aversion, respectively. Table 3 summarizes the equilibrium solutions under different situations.

In the next, we investigate the conditions under which the risk-neutral and the risk-averse GSCs can be improved by the RCS joint contract. All the conclusions are summarized in the following propositions and corollaries.

Proposition 3. When $\frac{g^{2}}{2 b \eta}<\frac{1-\phi}{1-\lambda}, \lambda=\phi$, and $w=\phi c$ hold together, the RCS joint contract can coordinate the riskneutral GSC.

Proposition 3 demonstrates that when certain conditions hold, the RCS joint contract is efficient in coordinating the risk-neutral GSC. Then, the expected profit of the GSC reaches the optimal level as the centralized GSC. In addition, it is possible for both members to negotiate on the contract parameters to allocate the coordinating profit and obtain more expected profits than those in the decentralized GSC.

Corollary 7. When the risk-neutral GSC is coordinated, we can obtain $E\left(\pi_{s}^{s *}\right)=(1-\lambda) E\left(\pi_{t}^{*}\right)=(1-\phi) E\left(\pi_{t}^{*}\right)$ and $E\left(\pi_{r}^{s *}\right)=\lambda E\left(\pi_{t}^{*}\right)=\phi E\left(\pi_{t}^{*}\right)$. The Pareto region in which both members' expected profits are improved is $\lambda \in\left[\frac{2 b \eta\left(2 b \eta-g^{2}\right)}{\left(4 b \eta-g^{2}\right)^{2}}, \frac{2 b \eta}{4 b \eta-g^{2}}\right]$ or $\phi \in\left[\frac{2 b \eta\left(2 b \eta-g^{2}\right)}{\left(4 b \eta-g^{2}\right)^{2}}, \frac{2 b \eta}{4 b \eta-g^{2}}\right]$.

Corollary 7 shows that, under the RCS joint contract framework, the risk-neutral supplier's expected profit is decreasing in the revenue-sharing ratio or the cost-sharing ratio, while it is opposite for the risk-neutral retailer's expected profit. It implies that the risk-neutral GSC's coordinating profit can be arbitrarily distributed between the members by adjusting the contract parameters. Hence, we obtain a region in which both members can obtain more expected profits under the RCS joint contract than those in the decentralized GSC.

Proposition 4. For the risk-averse GSC, in regions

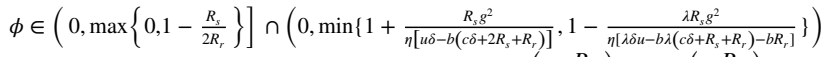
and $\lambda \in(0,1)$, we can obtain $E\left(\pi_{r}^{s R *}\right) \geq E\left(\pi_{r}^{R *}\right)$ and $E\left(\pi_{s}^{s R *}\right) \geq E\left(\pi_{s}^{R *}\right)$.

Proposition 4 demonstrates that, when specific conditions hold, the RSC joint contract is efficient in improving the risk-averse GSC. At the same time, if $R_{s} \geq 2 R_{r}$ holds, then $1-\frac{R_{s}}{2 R_{r}} \leq 0$, which means $\phi \leq 0$. This condition contradicts to the assumption that $0<\phi<1$. Hence, if and only if 


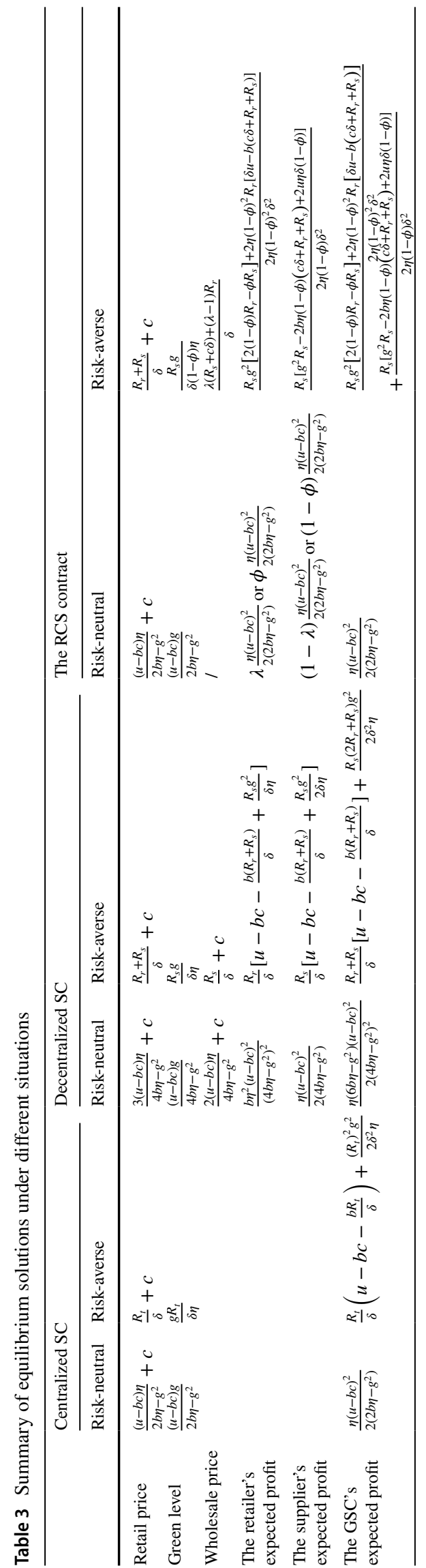

$R_{s}<2 R_{r}$, the RCS joint contract is valid, and it can improve the performance of the risk-averse GSC.

According to the above discussions, we conclude that through proper design of the RCS joint contract, the riskneutral GSC can be coordinated, and the coordinating profit can be arbitrarily allocated between the two members. However, the RCS joint contract can only improve the efficiency of the risk-averse GSC under specific conditions.

\section{Numerical examples}

In this section, numerical analyses are further conducted to validate our findings. We assume $u=500, R_{r}=550$, $R_{s}=550, R_{t}=1100, \delta=20, b=5, g=4, c=6$, and $\eta=8$. Then, the risk-neutral centralized GSC's optimal decisions are $p_{t}^{*}=64.75$ and $\theta_{t}^{*}=29.38$, and the corresponding expected profit is $E\left(\pi_{t}^{*}\right)=13806.25$. The riskaverse centralized GSC's optimal decisions are $p_{t}^{R *}=61$ and $\theta_{t}^{R *}=27.5$, and the corresponding expected profit is $E\left(\pi_{t}^{R *}\right)=13750$. Obviously, we can find $p_{t}^{*}>p_{t}^{R *}, \theta_{t}^{*}>\theta_{t}^{R *}$, and $E\left(\pi_{t}^{*}\right)>E\left(\pi_{t}^{R *}\right)$. All numerical analyses in the following are based on the above parameter settings.

\section{Sensitivity analysis on the centralized GSC}

In this subsection, sensitivity analyses are conducted to study the impacts of key parameters on the centralized GSC's optimal decisions and the expected profits. Particularly, we consider the situation when risk tolerance is valid, i.e., $R_{t}<R^{\prime}$. Then, based on the above parameter settings, we can obtain $R^{\prime}=1175$. Varying one parameter and keeping others constant, we obtain the valid ranges of different parameters in the riskaverse centralized GSC as follows: $u>470, b<5.26$, $g>3.41, \eta<11, \delta>18.72$, and $R_{t}<1175$.

Figure 1 shows how the optimal retail price changes with key parameters in a centralized GSC. (i) For the risk-neutral centralized GSC, the optimal retail price increases with $u$ and $g$ and decreases with $b$ and $\eta$; (ii) for the risk-averse centralized GSC, when $R_{t}<1175$, the optimal retail price decreases with $\delta$ but increases with $R_{t}$. Furthermore, the risk-averse GSC's optimal retail price is lower than that of the risk-neutral GSC when $R_{t}<1175$.

Figure 2 shows how the optimal green level changes with key parameters in a centralized GSC. (i) For the risk-neutral centralized GSC, the green level increases with $u$ and $g$ and decreases with $b$ and $\eta$; (ii) for the risk-averse centralized GSC, when $R_{t}<1175$, the optimal green level increases with $g$ and $R_{t}$ and decreases with $\eta$ and $\delta$. Furthermore, the risk-averse GSC's optimal green level is lower than that of the risk-neutral GSC when $R_{t}<1175$. 

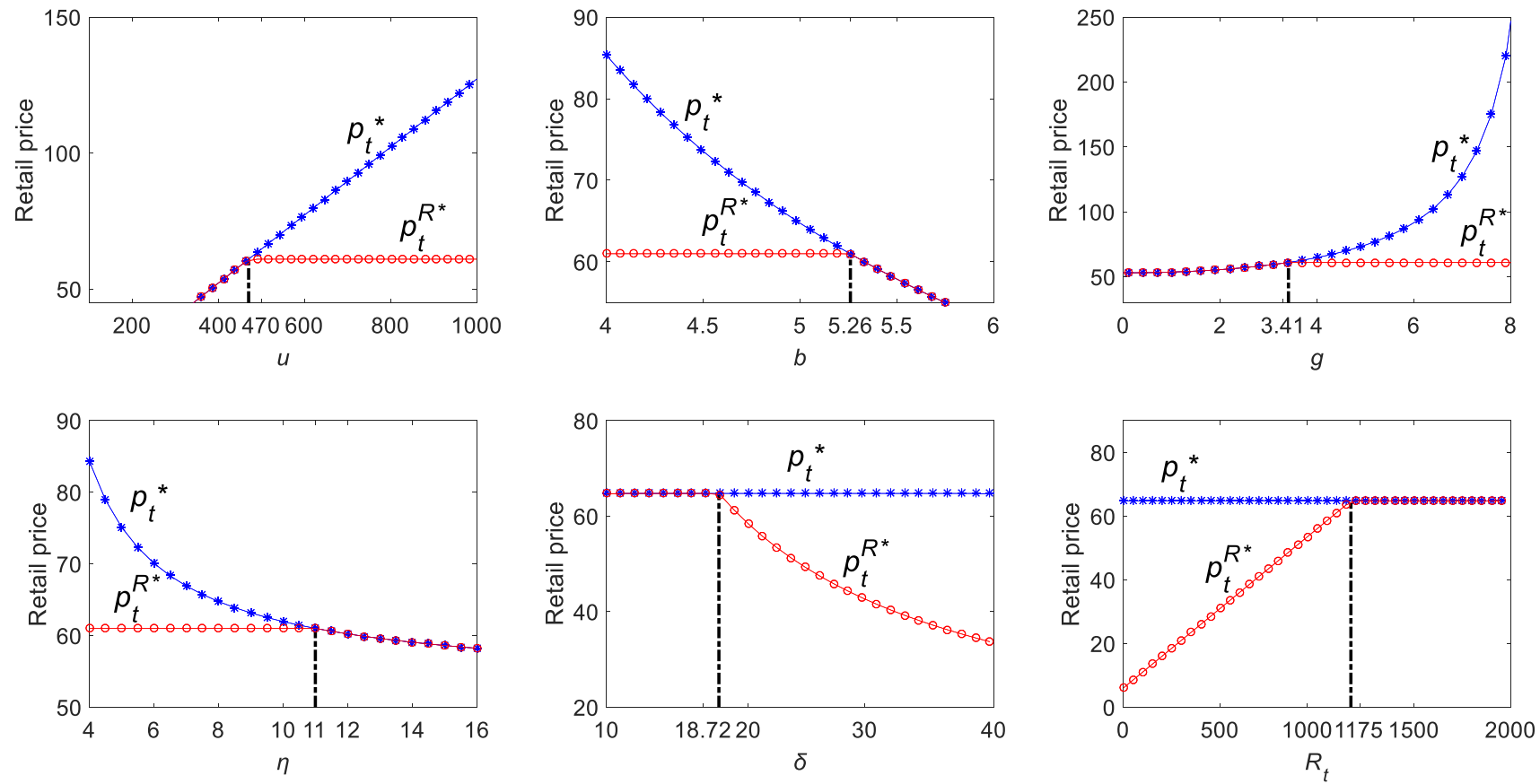

Fig. 1 Retail price decision of a centralized GSC: risk neutrality vs. risk aversion
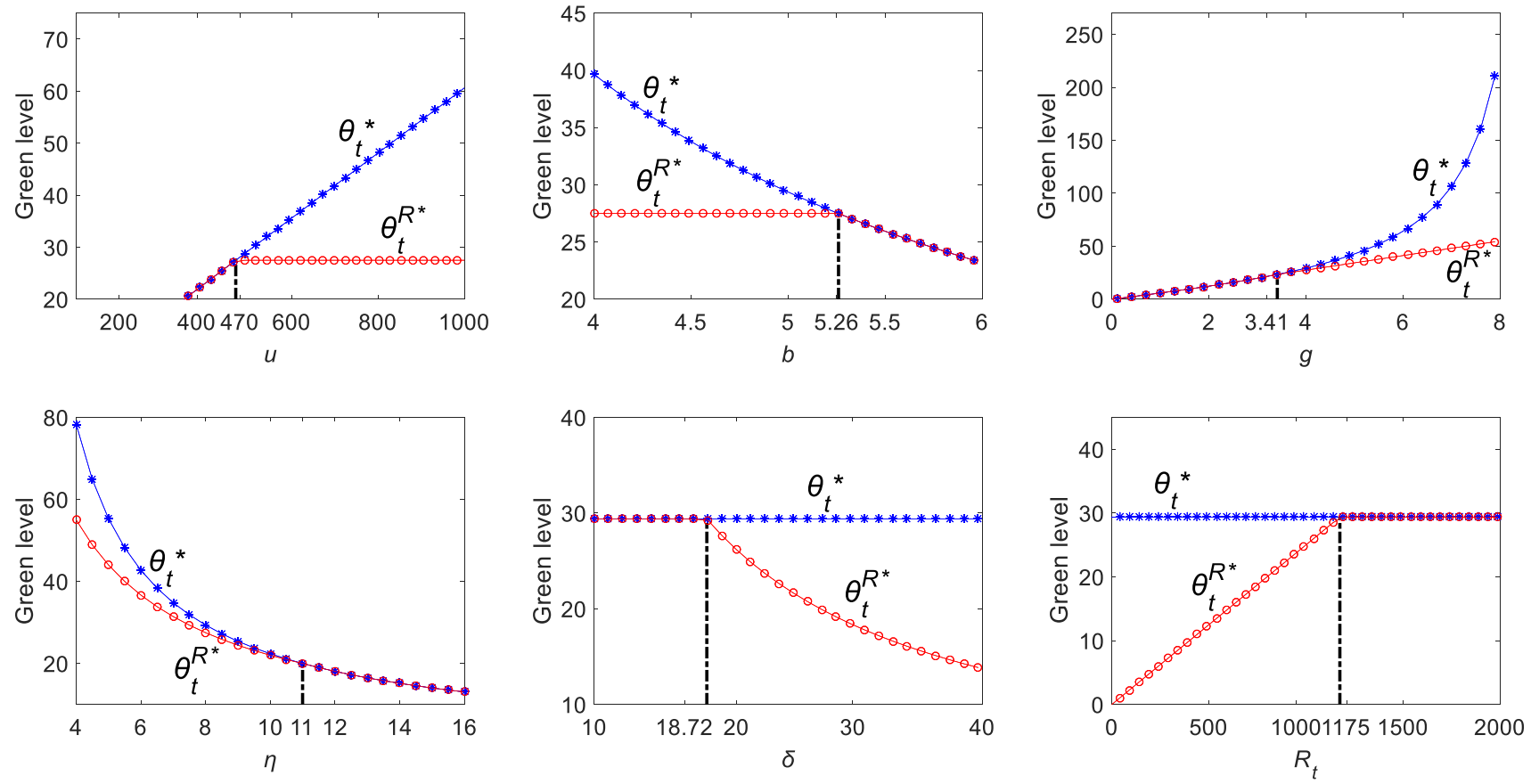

Fig. 2 Green level decision of a centralized GSC: risk neutrality vs. risk aversion

Figure 3 shows how the centralized GSC's optimal expected profits change with the parameters. ( $i$ ) It is evident that the risk-neutral centralized GSC's optimal expected profit increases with $u$ and $g$ and decreases with $b$ and $\eta$; (ii) for the risk-averse centralized GSC, when $R_{t}<1175$, the optimal expected profit increases with $u, g$, and $R_{t}$ and decreases with $b, \eta$, and $\delta$. Furthermore, the risk-averse centralized GSC's optimal expected profit is lower than that of the risk-neutral centralized GSC when $R_{t}<1175$. 

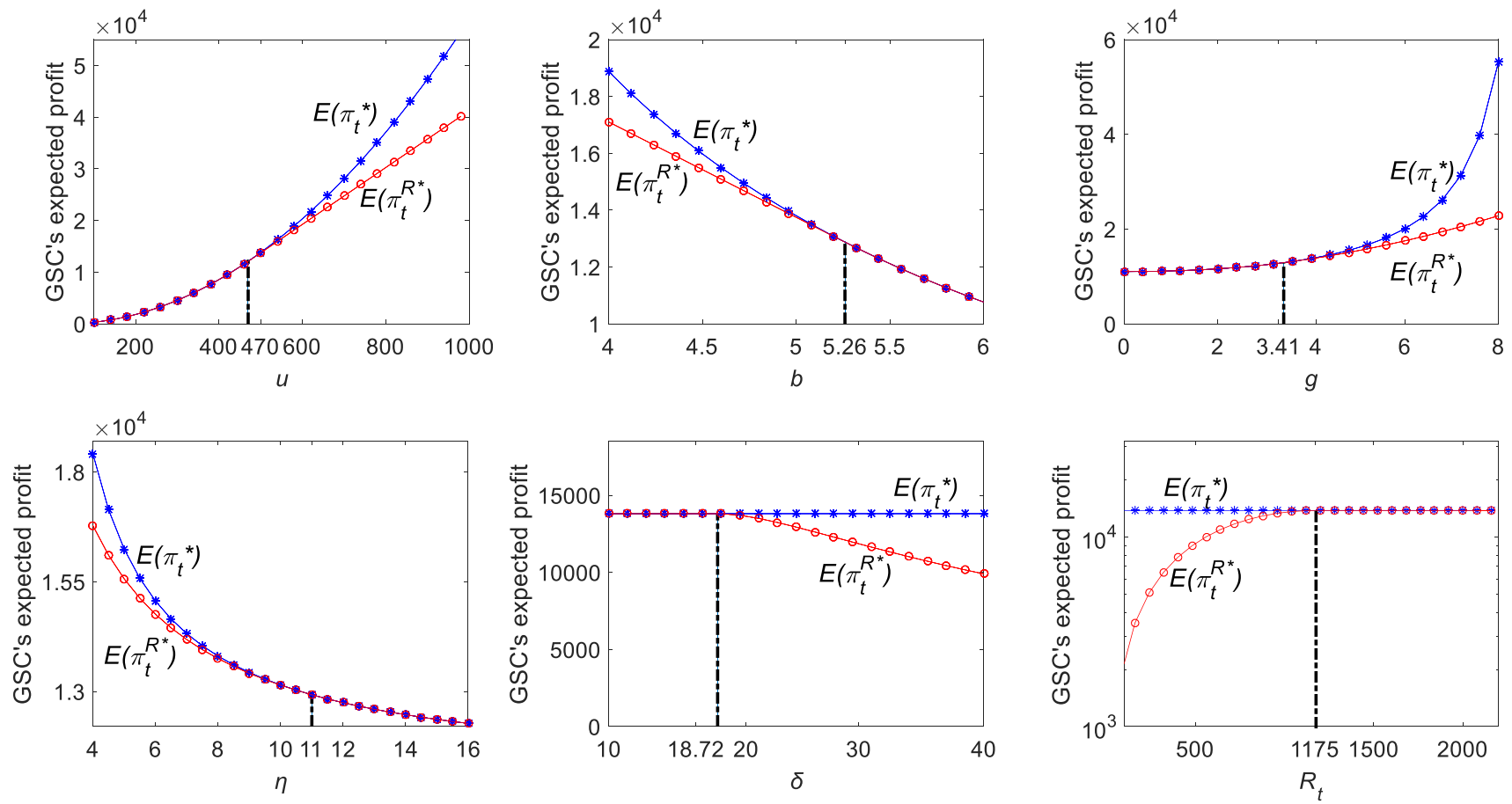

Fig. 3 Expected profit of a centralized GSC: risk neutrality vs. risk aversion

\section{Sensitivity analysis on the decentralized GSC}

Now, we examine how the decentralized GSC's optimal decisions and expected profits change with key parameters. Given the above parameter settings, we can calculate $R_{r}^{d^{\prime}}=723, \quad R_{s}^{d^{\prime}}=723, \quad R_{r}^{d t}=202.37, \quad R_{s}^{d t}=553.1$ $R_{r}^{d h}=231.62, \quad R_{s}^{d h}=32.97, \quad$ a n d $\quad \frac{(u-b c) \delta}{b}$ $\left(1-\sqrt{\frac{2 b \eta-g^{2}}{4 b \eta-g^{2}}}\right)=626.67$.

First, for the risk-neutral decentralized GSC, we obtain the optimal solutions $\theta^{d *}=13.06, p^{d *}=84.33$, and $w^{d *}=58.22$ under the above parameter settings. Thus, the optimal expected profits of the retailer, the supplier, and the GSC are $E\left(\pi_{r}^{d *}\right)=3408.95, E\left(\pi_{s}^{d *}\right)=6136.11$, and $E\left(\pi_{t}^{d *}\right)=9545.06$, respectively. Similarly, for the risk-averse decentralized GSC, we consider the situation when the risk tolerance is valid, i.e., $R_{r}<723$ and $R_{s}<723$. If $R_{r}=550$ and $R_{s}=550$, we obtain the optimal decisions $\theta^{d R *}=13.75, p^{d R *}=61$, and $w^{d R *}=33.5$, and the optimal expected profits of the retailer, the supplier, and the GSC are $E\left(\pi_{r}^{d R *}\right)=6875, E\left(\pi_{s}^{d R *}\right)=6118.75$, and $E\left(\pi_{t}^{d R *}\right)=12993.75$, respectively. It is easy to find that $\theta^{d *}<\theta^{d R *}, p^{d *}>p^{d R *}$, and $w^{d *}>w^{d R *}$. Moreover, we obtain $E\left(\pi_{r}^{d R *}\right)>E\left(\pi_{r}^{d *}\right), E\left(\pi_{s}^{d R *}\right)<E\left(\pi_{s}^{d *}\right)$, and $E\left(\pi_{t}^{d R *}\right)>E\left(\pi_{t}^{d *}\right)$.

In the next, we vary one parameter and keep others constant and obtain the valid ranges of the parameters in the risk-averse decentralized GSC as follows: $u>387.5$, $b<6.79, g>0, \delta>15.21, R_{r}<723$, and $R_{s}<723$. It can be easily obtained that the impacts of the mean value of the market potential, the green elastic coefficient, the price elastic coefficient, the standard variance of the market potential, and the risk tolerance on the optimal retail price in the decentralized GSC are similar to those in the centralized GSC. Figure 4 shows how the optimal retail price changes with the risk tolerance of both members when $R_{r}<723$ and $R_{s}<723$. Given $R_{r}=550$, the optimal retail price increases with $R_{s}$. Similary, given $R_{s}=550$, the optimal retail price increases with $R_{r}$. Specifically, the risk-averse decentralized GSC's optimal retail price is always lower than that of the risk-neutral decentralized GSC when risk tolerances of both members satisfy $R_{r}<723$ and $R_{s}<723$. This reveals that the retailer is more cautious in decision-making and chooses a lower retail price when she is risk averse. Then the conclusions about retail price in Corollary $4(a)$ are verified.

Figure 5 shows how the optimal green level in the decentralized GSC changes with key parameters. It can easily observe that the impacts of the mean value of the market potential, the green elastic coefficient, the price elastic coefficient, and the standard variance of the market potential on the optimal green level in the decentralized GSC are similar to those in the centralized GSC. However, for the riskaverse decentralized GSC, the optimal green level is closely related to $R_{s}$ and is independent of $R_{r}$. Moreover, given the parameter settings, we find that when $387.5<u \leq 525$, or $4.78 \leq b<6$, or $0<g \leq 4.82$, or $15.21<\delta \leq 21.06$, 
Fig. 4 Retail price decision in a decentralized GSC: risk neutrality vs. risk aversion
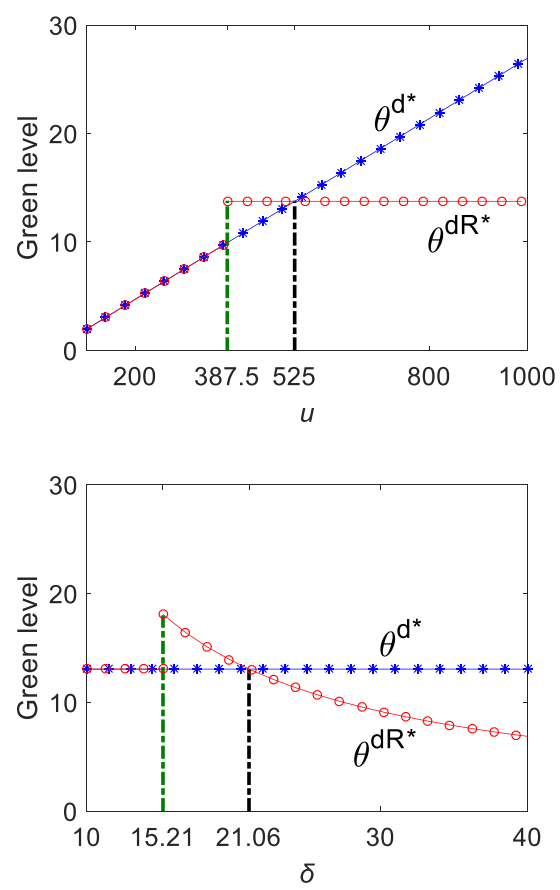
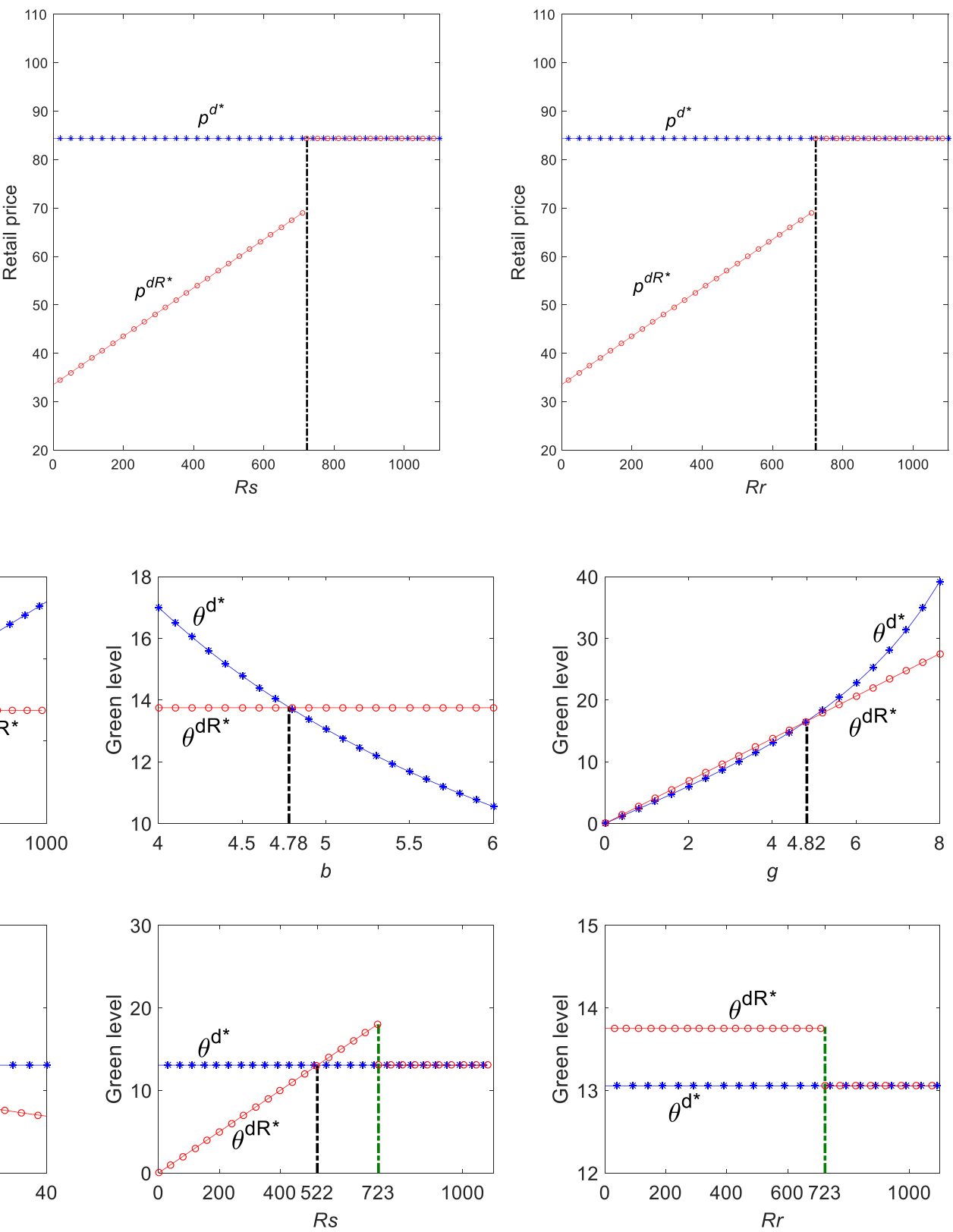

Fig. 5 Green level decision in a decentralized GSC: risk neutrality vs. risk aversion

or $R_{s} \geq 522$, or $R_{r} \leq 723$, there is $\theta^{d R *} \geq \theta^{d *}$; and when $525<u<1000$, or $0<b<4.78$, or $4.82<g<8$, or $21.06<\delta<40$, or $R_{s}<522$, there is $\theta^{d R *}<\theta^{d *}$. Hence, the conclusions stated in Corollary $4(b)$ are illustrated.

Figure 6 shows how the optimal wholesale price changes with key parameters in the decentralized GSC. (i) For the risk-neutral decentralized GSC, the optimal wholesale price increases with $u$ and $g$ and decreases with $b$; (ii) for the risk-averse decentralized GSC, the optimal wholesale price increases with $R_{s}$ and decreases with $\delta$. Furthermore, Fig. 6 demonstrates that the supplier's optimal wholesale price in the risk-averse decentralized GSC is lower than that in the risk-neutral decentralized GSC when $R_{r}<723$ and $R_{s}<723$. Hence, the conclusions about the wholesale price in Corollary $4(a)$ are verified.

In the next, we further compare the differences in all members' expected profits between the decentralized GSCs with risk neutrality and risk aversion through sensitivity analyses. Figure 7 shows how the retailer's optimal expected profit changes with key parameters. (i) For the risk-neutral decentralized GSC, the retailer's optimal expected profit increases with $u$ and $g$ and decreases with $b$; (ii) for the riskaverse decentralized GSC, the retailer's optimal expected 

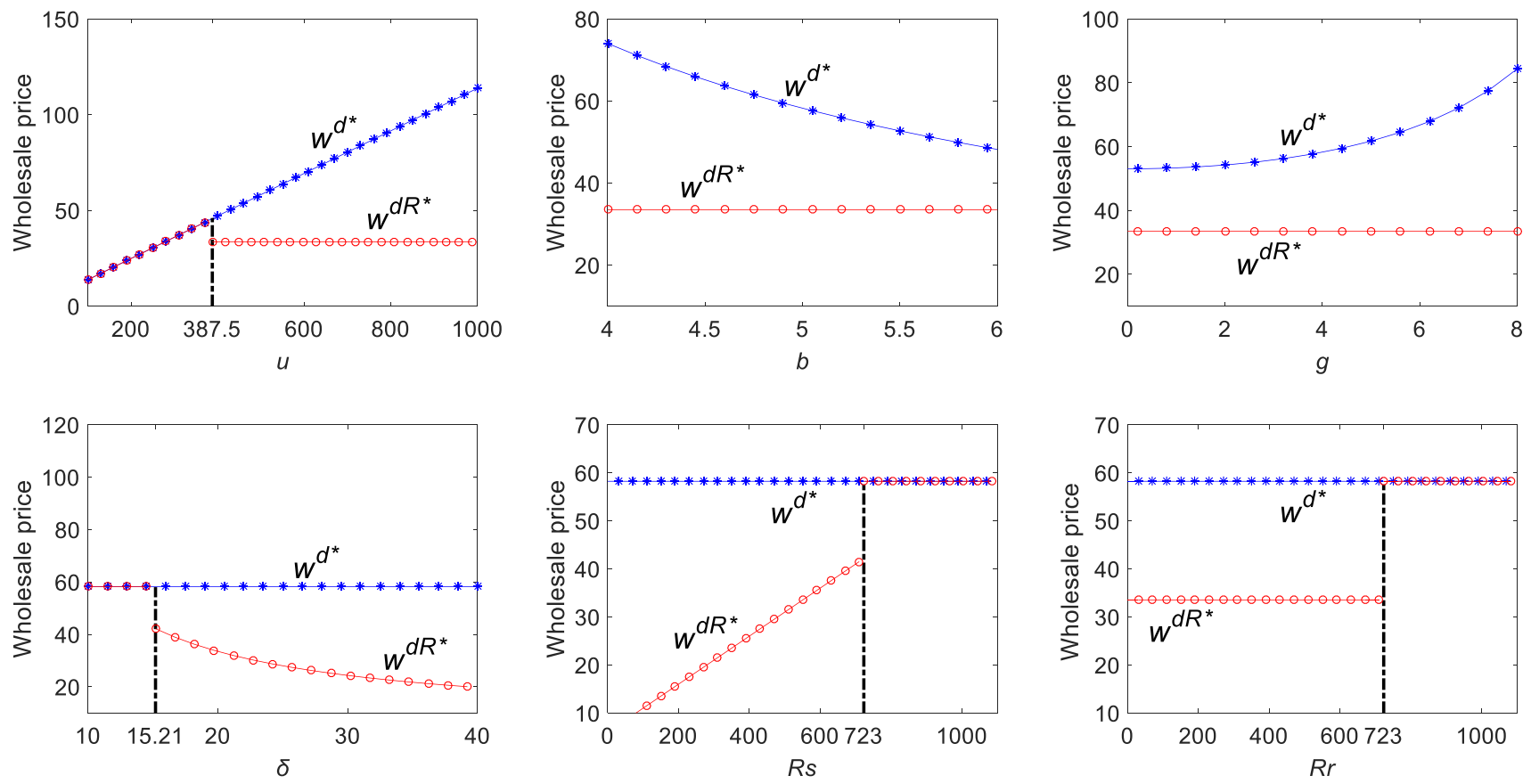

Fig. 6 Wholesale price decision in a decentralized GSC: risk neutrality vs. risk aversion
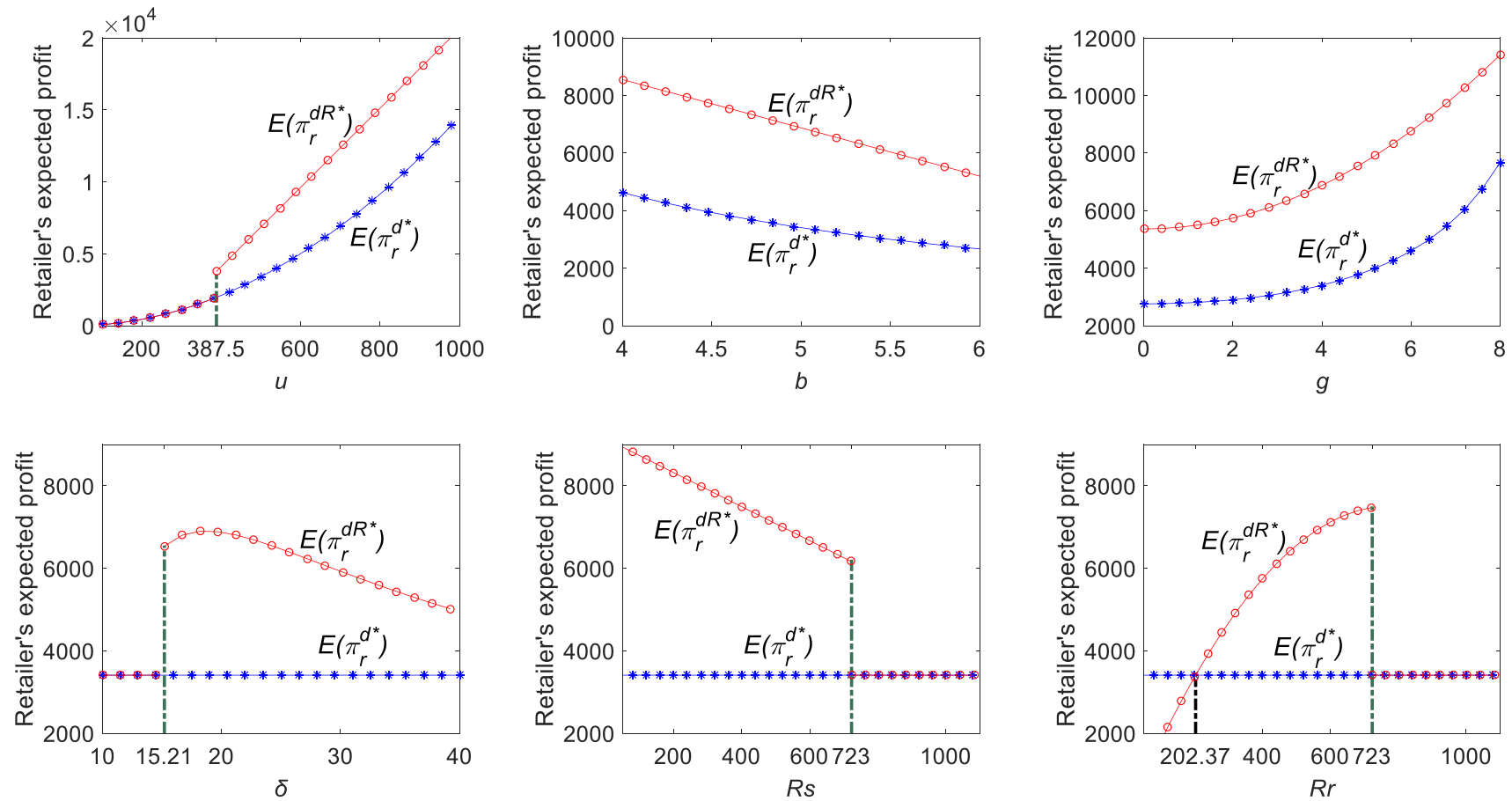

Fig. 7 Retailer's expected profit in a decentralized GSC: risk neutrality vs. risk aversion

profit increases with $u, g$, and $R_{r}$, decreases with $b$ and $R_{s}$, and the first increases and then decreases with $\delta$ when $R_{r}<723$ and $R_{s}<723$.
Given $R_{s}=550$, if $0<R_{r}<202.37$, the risk-averse retailer's optimal expected profit is lower than that of the risk-neutral retailer; given $R_{s}=550$, if $202.37<R_{r}<723$, 

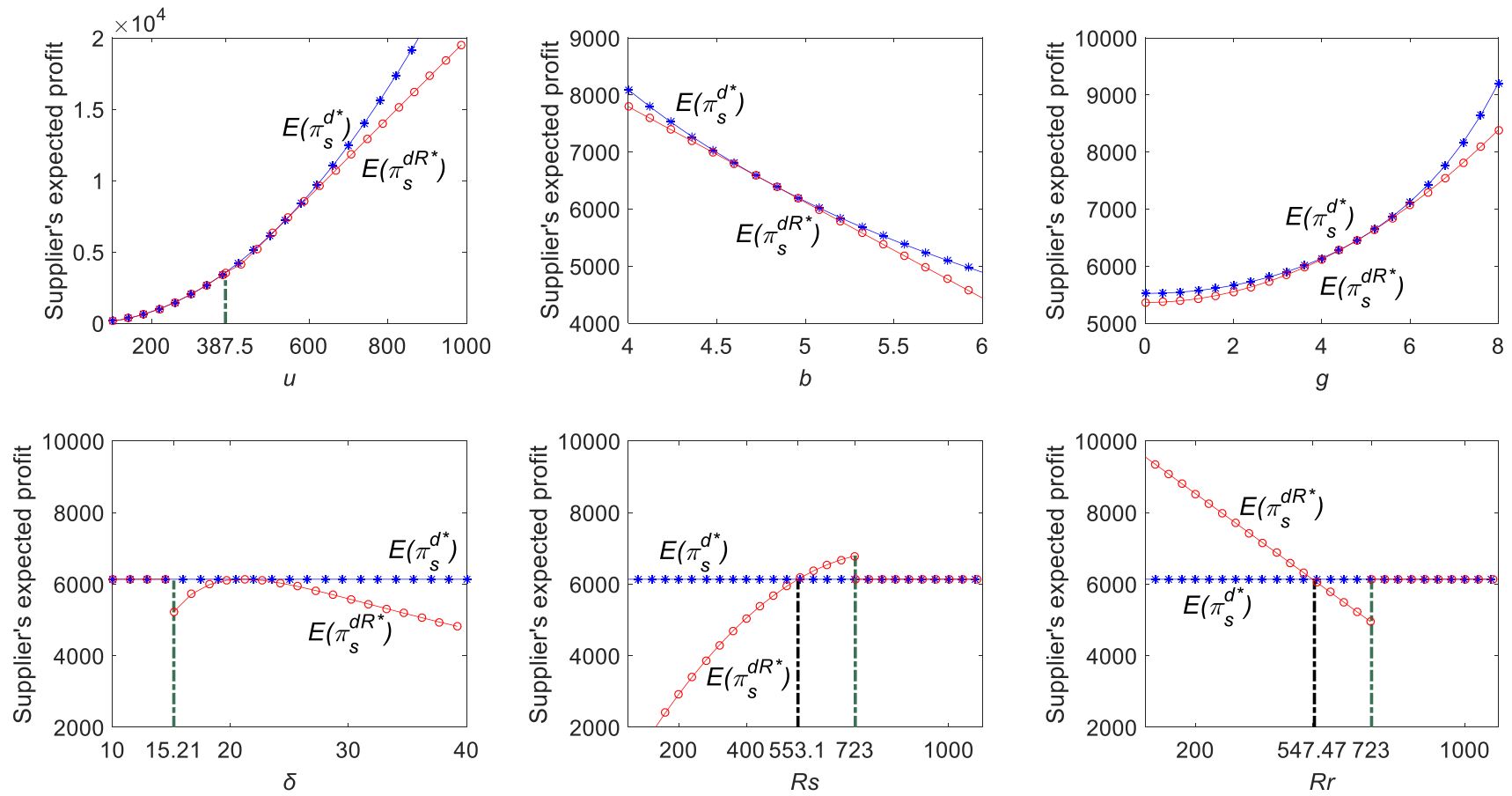

Fig. 8 Supplier's expected profit in a decentralized GSC: risk neutrality vs. risk aversion

we can reach the opposite conclusion. Then the conclusions as stated in Corollary $4(c)$ are numerically verified.

Figure 8 shows how the supplier's optimal expected profit in the decentralized GSC changes with key parameters. (i) We find that, in the risk-neutral decentralized GSC, the supplier's optimal expected profit increases with $u$ and $g$ and decreases with $b$; (ii) for the risk-averse decentralized GSC, the supplier's optimal expected profit increases with $u, g$, and $R_{s}$ and decreases with $b$ and $R_{r}$, and the first increases and then decreases with $\delta$ when $R_{r}<723$ and $R_{s}<723$.

Given $R_{r}=550$, if $0<R_{s}<553.1$, the risk-averse supplier's expected profit is lower than that of the risk-neutral supplier; if $553.1<R_{s}<723$, we can obtain the opposite conclusion. Given $R_{s}=550$, if $0<R_{r} \leq 547.47$, we have $0<R_{s}^{d t} \leq 550$ and $R_{s}^{d t} \leq R_{s}<723$, and then the riskaverse supplier's expected profit is higher than that of the risk-neutral supplier; if $547.47<R_{r}<626.67$, we have $550<R_{s}^{d t}<723$ and $R_{s}<R_{s}^{d t}$, and then the risk-averse supplier's expected profit is lower than that of the risk-neutral supplier; if $626.67 \leq R_{r}<723$, then the risk-averse supplier's expected profit is lower than that of the risk-neutral supplier. Then the conclusions in Corollary $4(d)$ are illustrated.

Figure 9 shows how the decentralized GSC's total expected profit changes with key parameters. (i) For the risk-neutral GSC, it is evident that the total expected profit increases with $u$ and $g$ and decreases with $b$; (ii) for the risk-averse GSC, the total expected profit increases with $u$ and $g$ and decreases with $b$, and the first increases and then decreases with $\delta, R_{s}$, and $R_{r}$ when $R_{r}<723$ and $R_{s}<723$.
Given $R_{r}=550$, then $231.62 \leq R_{r}<723$ holds, the risk-averse decentralized GSC's total expected profit is higher than that of the risk-neutral decentralized GSC when $R_{s}<723$; given $R_{s}=550$, we have $R_{s}>32.97$ holds, then the risk-averse decentralized GSC's total expected profit is higher than that of the risk-neutral decentralized GSC when $R_{r}<723$. Then the conclusions in Corollary 4 are illustrated.

\section{Coordination mechanisms}

In this paper, an RCS joint contract is proposed, and we find that when $\frac{g^{2}}{2 b \eta}<\frac{1-\phi}{1-\lambda}, \lambda=\phi$, and $w=\phi c$ hold together, the risk-neutral GSC is coordinated. Given the above parameters, for the risk-neutral GSC, the value $\phi$ varies from 0 to 1 , which is derived from the condition $\frac{g^{2}}{2 b \eta}<\frac{1-\phi}{1-\lambda}$ and $\lambda=\phi$. Figure 10 shows how the members' expected profits change with $\phi$ when the risk-neutral GSC is coordinated. We find that under the RCS joint contract, the risk-neutral retailer's expected profit is always increasing in $\phi$, while the riskneutral supplier's expected profit is always decreasing in $\phi$. Then, the Pareto region in the risk-neutral GSC is $\phi \in[0.2469,0.5556]$. We further analyze how the risk-averse GSC members' expected profits change with $\lambda$ and $\phi$, as shown in Fig. 11. Obviously, when $\phi$ is relatively small, i.e., locating in the range $\phi \in\left(0, \frac{1}{23}\right)$, both risk-averse members can obtain more expected profits than those in the risk-averse 

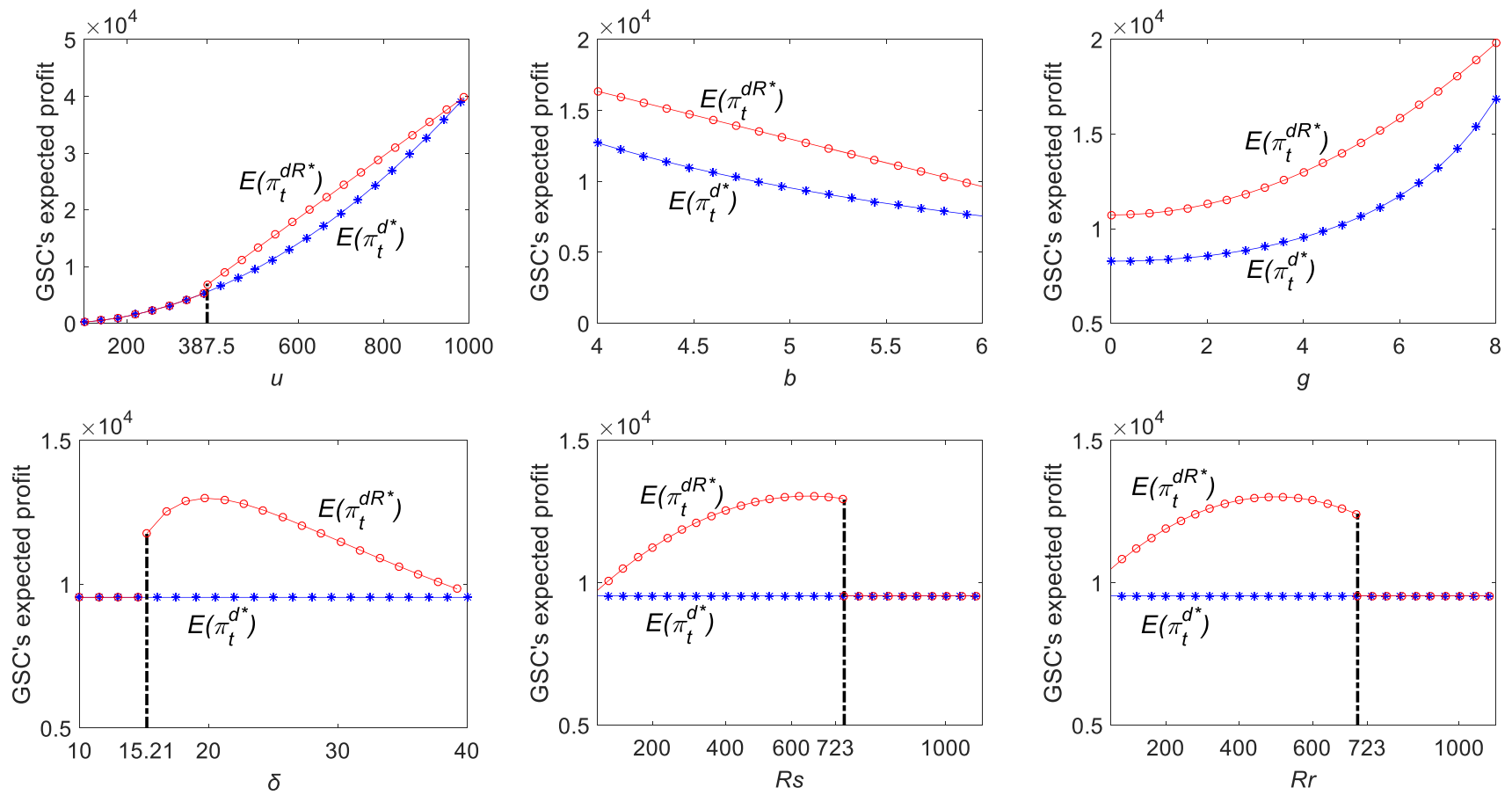

Fig. 9 The decentralized GSC's expected profit: risk neutrality vs. risk aversion

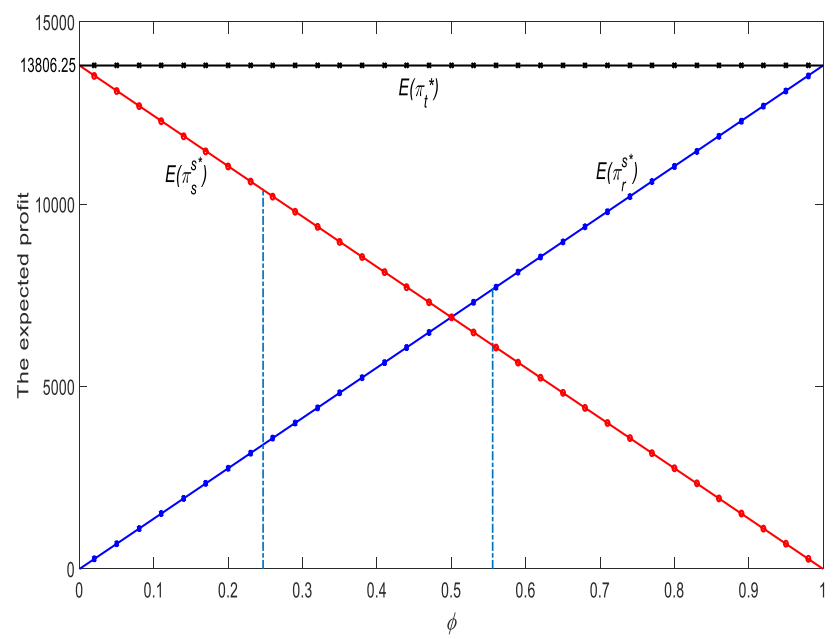

Fig. 10 The risk-neutral GSC members' expected profits change with $\phi$

decentralized GSC without introducing the RCS joint contract.

\section{Conclusions and discussions}

In this paper, we develop a risk-averse GSC with a supplier producing green products and selling products in the market through a retailer. The MV model is applied to measure

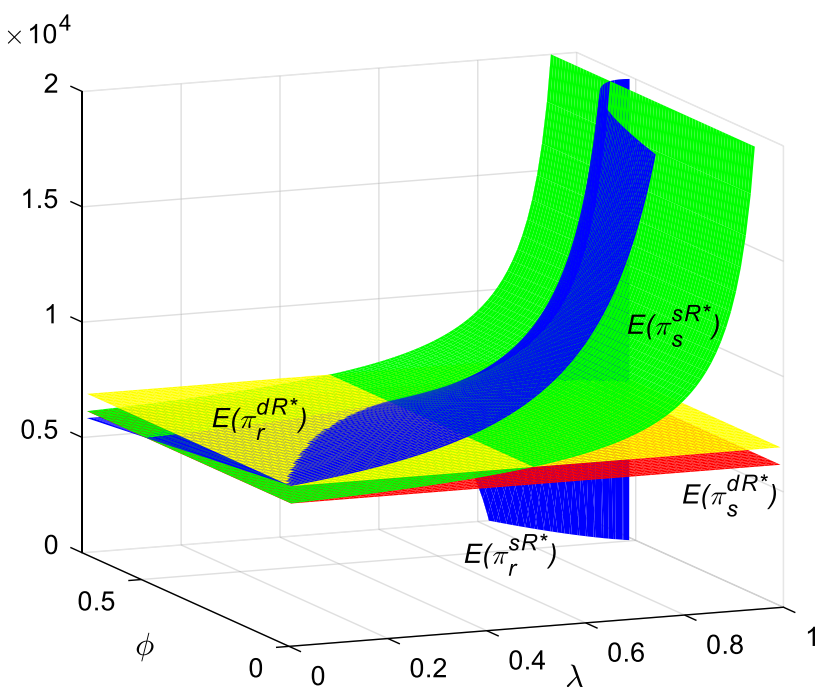

Fig. 11 The risk-averse GSC members' expected profits change with $\lambda$ and $\phi$

the members' risk-averse attitudes, and a risk tolerance is adopted to reflect the degree of risk aversion.

We first investigate the centralized GSCs with risk neutrality and risk aversion, and the optimal retail prices, green levels, and corresponding expected profits are derived and compared. Our finding shows that, when risk tolerance is valid, the risk-averse centralized GSC always chooses a lower green level and a lower retail price than the 
risk-neutral GSC. Hence, the risk-averse GSC's expected profit is lower than that of the risk-neutral GSC.

Then, we investigate the decentralized GSC in which the two members make decisions by maximizing their own benefits. We then obtain the equilibrium solutions of the decentralized GSCs with risk neutrality and risk aversion. The results demonstrate that, when the risk tolerance is valid, the risk-averse supplier's wholesale price is lower than that of the risk-neutral supplier, and the risk-averse retailer's retail price is lower than that of the risk-neutral retailer. However, the supplier may choose a higher green level when he is not severely risk-averse. We also find that both members' optimal expected profits may be increased when they are risk averse under specific conditions.

Furthermore, we propose an RCS joint contract to improve the performances of both the risk-neutral GSC and the risk-averse GSC. We find that, whether the GSC is risk averse or risk neutral, the contract is effective in improving the GSC. Specifically, the RCS joint contract is able to coordinate the risk-neutral GSC, and the coordinating profit can be flexibly allocated between the two members by adjusting the revenue-sharing ratio or the cost-sharing ratio. For the risk-averse GSC, the RCS joint contract is efficient under specific conditions, but it may be invalid when the supplier's risk tolerance is twice higher than the retailer's risk tolerance.

Although our study makes innovative contributions to the literature, there still exist several directions for future researches. For instance, information may be asymmetric in practice, and it may be necessary to examine the competitive equilibrium under asymmetric information settings. Furthermore, as there may be multiple suppliers and retailers involved in GSC activities, the decision-makers should decide how to allocate their production quantity while considering price- and green-level strategies.

\section{Appendix}

\section{Proof of Proposition 1}

\section{Risk neutral}

Taking the second-order partial derivatives of $E\left(\pi_{t}\right)$ with respect to $p$ and $\theta$, we have the Hessian matrix:

$H=\left(\begin{array}{ll}\frac{\partial^{2} E\left(\pi_{t}\right)}{\partial p^{2}} & \frac{\partial^{2} E\left(\pi_{t}\right)}{\partial p \partial \theta} \\ \frac{\partial^{2} E\left(\pi_{t}\right)}{\partial \theta \partial p} & \frac{\partial^{2} E\left(\pi_{t}\right)}{\partial \theta^{2}}\end{array}\right)=\left(\begin{array}{cc}-\eta & g \\ g & -2 b\end{array}\right)$

It is obvious that $\frac{\partial^{2} E\left(\pi_{t}\right)}{\partial p^{2}}<0$ and $\frac{\partial^{2} E\left(\pi_{t}\right)}{\partial \theta^{2}}<0$. Because $\eta>g$ and $b>g$, we obtain $|H|=2 \eta b-g^{2}>0$. Then, the
Hessian $H$ is a negative definite, which means that $E\left(\pi_{t}\right)$ is jointly concave in $p$ and $\theta$. Hence, the optimal retail price and green level in the risk-neutral centralized GSC can be derived in the following.

$p_{t}^{*}=\frac{(u-b c) \eta}{2 b \eta-g^{2}}+c$

$\theta_{t}^{*}=\frac{(u-b c) g}{2 b \eta-g^{2}}$

\section{Risk averse}

$E\left(\pi_{t}\right)$ is jointly concave in $p$ and $\theta$, and the constraint $\sqrt{\operatorname{Var}\left(\pi_{t}\right)} \leq R_{t}$ is convex; we conclude that the optimization problem (2) is a convex optimization problem, whose optimal solution can be derived by Karush-Kuhn-Tucker (KKT) conditions. We then construct the Lagrange function as follows.

$L^{R}\left(p, \theta, r_{0}\right)=E\left(\pi_{t}\right)+r_{0}\left(R_{t}-\sqrt{\operatorname{Var}\left(\pi_{t}\right)}\right)$

Here, $r_{0}$ denotes the multiplier for the constraint. From the first-order KKT condition, we can get $p_{t}^{R *}=$ $\frac{R_{t}}{\delta}+c, \theta_{t}^{R *}=\frac{g R_{t}}{\delta \eta}, r_{0}=\frac{u-b c}{\delta}-\frac{2 b R_{t}}{\delta^{2}}+\frac{g^{2} R_{t}}{\delta^{2} \eta}$

Owing that $R_{t}<R^{\prime}$, where $R^{\prime}=\frac{(u-b c) \delta \eta}{2 b \eta-g^{2}}$, we obtain $r_{0}>0$. Hence, the optimal decisions of the risk-averse centralized GSC are $p_{t}^{R *}=\frac{R_{t}}{\delta}+c$ and $\theta_{t}^{R *}=\frac{g R_{t}}{\delta \eta}$.

Proof of Corollary 1. It is straightforward and the details are omitted here.

Proof of Corollary 2. Because $p_{t}^{*}-p_{t}^{R *}=$ $\frac{(u-b c) \eta}{2 b \eta-g^{2}}-\frac{R_{t}}{\delta}>\frac{(u-b c) \eta}{2 b \eta-g^{2}}-\frac{(u-b c) \eta}{2 b \eta-g^{2}}=0$, we obtain $p_{t}^{R *}<p_{t}^{*}$. At the same time, we find $\frac{\theta_{t}^{*}}{\theta_{t}^{R *}}=\frac{\delta \eta(u-b c)}{\left(2 b \eta-g^{2}\right) R_{t}}>1$ and then $\theta_{t}^{R *}<\theta_{t}^{*}$.

Recall that $E\left(\pi_{t}\right)$ is concave in $R_{t}$ If $R_{t}=\frac{(u-b c) \delta \eta}{2 b \eta-g^{2}}$, then we can have $E\left(\pi_{t}^{R *}\right)=\frac{\eta(u-b c)^{2}}{2\left(2 b \eta-g^{2}\right)}$. Because $R_{t}<R^{\prime}$, then $E\left(\pi_{t}^{R *}\right)<E\left(\pi_{t}^{*}\right)$.

\section{Proof of Proposition 2}

\section{Risk neutral}

Taking the second-order partial derivatives of $E\left(\pi_{r}^{d}\right)$ with respect to $p$, we have the following:

$\frac{\partial^{2} E\left(\pi_{r}^{d}\right)}{\partial p^{2}}=-2 b<0$

Therefore, $E\left(\pi_{r}^{d}\right)$ is concave in $p$; hence, the retailer's optimal retail price is as follows: 
$p^{d *}(w, \theta)=\frac{u+g \theta+b w}{2 b}$

Substitute $p^{d *}$ into Eq. (7), then take the second-order partial derivatives of $E\left(\pi_{s}^{d}\right)$ with respect to $w$ and $\theta$, and we have the Hessian matrix in the following.

$H=\left(\begin{array}{ll}\frac{\partial^{2} E\left(\pi_{s}^{d}\right)}{\partial \theta^{2}} & \frac{\partial E^{2}\left(\pi_{s}^{d}\right)}{\partial \theta \partial w^{d}} \\ \frac{\partial E^{2}\left(\pi_{s}^{d}\right)}{\partial w \partial \theta} & \frac{\partial^{2} E\left(\pi_{s}^{d}\right)}{\partial w^{2}}\end{array}\right)=\left(\begin{array}{cc}-\eta & \frac{g}{2} \\ \frac{g}{2} & -b\end{array}\right)$

Because $\frac{\partial^{2} E\left(\pi_{s}^{d}\right)}{\partial \theta^{2}}<0, \frac{\partial^{2} E\left(\pi_{s}^{d}\right)}{\partial w^{2}}<0$, and $|H|=\eta b-\frac{g^{2}}{4}>0$, the Hessian $H$ is a negative definite. $E\left(\pi_{s}^{d}\right)$ is jointly concave in $w$ and $\theta$; hence, the optimal wholesale price and green level in risk-neutral GSC are as follows:

$w^{d *}=\frac{2 \eta(u-b c)}{4 b \eta-g^{2}}+c$ and $\theta^{d *}=\frac{g(u-b c)}{4 b \eta-g^{2}}$

Substituting $w^{d *}$ and $\theta^{d *}$ into the expression of $p^{d *}(w, \theta)$, we can have the following:

$p^{d *}=\frac{3(u-b c) \eta}{4 b \eta-g^{2}}+c$

Hence, the optimal decisions of the risk-neutral decentralized GSC are as follows:

$p^{d *}=\frac{3(u-b c) \eta}{4 b \eta-g^{2}}+c, w^{d *}=\frac{2 \eta(u-b c)}{4 b \eta-g^{2}}+c, \theta^{d *}=\frac{g(u-b c)}{4 b \eta-g^{2}}$

\section{Risk averse.}

$E\left(\pi_{r}^{d}\right)$ is concave in $p$ and the constraint $\sqrt{\operatorname{Var}\left(\pi_{r}^{d}\right)} \leq R_{r}$ is convex, we conclude that the optimization problem (5) is a convex optimization problem, whose optimal solution can be derived by KKT conditions. Then, we can construct the Lagrange function as follows.

$L_{r}^{d}\left(p, r_{1}\right)=E\left(\pi_{r}^{d}\right)+r_{1}\left(R_{r}-\sqrt{\operatorname{Var}\left(\pi_{r}^{d}\right)}\right)$

From the first-order KKT condition, we can get the following:

$p^{d R *}(w, \theta)=\frac{R_{r}}{\delta}+w, r_{1}=\frac{u+g \theta-b w}{\delta}-\frac{2 b R_{r}}{\delta^{2}}$

Substitute $p^{d R *}(w, \theta)$ into supplier's expected profit, then take the second-order partial derivatives of $E\left(\pi_{s}^{d}\right)$ with respect to $w$ and $\theta$, and we have the Hessian matrix in the following.

$H=\left(\begin{array}{ll}\frac{\partial^{2} E\left(\pi_{s}^{d}\right)}{\partial \theta^{2}} & \frac{\partial E^{2}\left(\pi_{s}^{d}\right)}{\partial \theta \partial w} \\ \frac{\partial E^{2}\left(\pi_{s}^{d}\right)}{\partial w \partial \theta} & \frac{\partial^{2} E\left(\pi_{s}^{d}\right)}{\partial w^{2}}\end{array}\right)=\left(\begin{array}{cc}-\eta & g \\ g & -2 b\end{array}\right)$

Because $\frac{\partial^{2} E\left(\pi_{s}^{d}\right)}{\partial \theta^{2}}<0, \frac{\partial^{2} E\left(\pi_{s}^{d}\right)}{\partial w^{2}}<0$, and $|H|=2 \eta b-g^{2}>0$, the Hessian $H$ is a negative definite. $E\left(\pi_{s}^{d}\right)$ is jointly concave in $w$ and $\theta$. Meanwhile, the constraint $\sqrt[s]{\operatorname{Var}\left(\pi_{s}^{d}\right)} \leq R_{s}$ is con- vex. Therefore, we conclude that the optimization problem (8) is a convex optimization problem, whose optimal solution can be derived by KKT conditions. Then, we can construct the Lagrange function as follows.

$L_{s}^{d}\left(w, \theta, r_{2}\right)=E\left(\pi_{s}^{d}\right)+r_{2}\left(R_{s}-\sqrt{\operatorname{Var}\left(\pi_{s}^{d}\right)}\right)$

From the first-order KKT condition, we can get the following:

$$
\begin{gathered}
w^{d R *}=\frac{R_{s}}{\delta}+c \text { and } \theta^{d R *}=\frac{R_{s} g}{\delta \eta} . \\
r_{1}=\frac{u-b c}{\delta}-\frac{1}{\delta^{2}}\left(2 b R_{r}+b R_{s}-\frac{R_{s} g^{2}}{\eta}\right) \\
\text { and } r_{2}=\frac{u-b c}{\delta}-\frac{1}{\delta^{2}}\left(b R_{r}+2 b R_{s}-\frac{R_{s} g^{2}}{\eta}\right)
\end{gathered}
$$

Owing that $R_{r}<R_{r}^{d^{\prime}}$ and $R_{s}<R_{s}^{d^{\prime}}$, where $R_{r}^{d^{\prime}}=\frac{(u-b c) \delta \eta}{3 b \eta-g^{2}}$ and $R_{s}^{d^{\prime}}=\frac{(u-b c) \delta \eta}{3 b \eta-g^{2}}$, we obtain $r_{1}>0$ and $r_{2}>0$.

Substituting $w^{d R *}$ and $\theta^{d R *}$ into the expression of $p^{d R *}(w, \theta)$, we can have the following:

$p^{d R *}=\frac{R_{r}+R_{s}}{\delta}+c$

Hence, the optimal decisions of risk-averse decentralized GSC are as follows:

$p^{d R *}=\frac{R_{r}+R_{s}}{\delta}+c, w^{d R *}=\frac{R_{s}}{\delta}+c, \theta^{d R *}=\frac{R_{s} g}{\delta \eta}$

Proof of Corollary 3. It is straightforward and the details are omitted here.

\section{Proof of Corollary 4}

a) Because $\frac{p^{d *}-c}{p^{d R^{*}}-c}=\frac{3 \eta(u-b c)}{4 b \eta-g^{2}} \frac{\delta}{R_{r}+R_{s}}>\frac{9 b \eta-3 g^{2}}{8 b \eta-2 g^{2}}>1$, we can get $p^{d R *}<p^{d *}$. At the same time, because $\frac{w^{d *}-c}{w^{d R *}-c}=$ $\frac{2(u-b c) \eta}{4 b \eta-g^{2}} \frac{\delta}{R_{s}}>\frac{2(u-b c) \eta}{4 b \eta-g^{2}} \frac{3 b \eta-g^{2}}{(u-b c) \eta}>1$, we can get $w^{d R *}<w^{d *}$

b) When $\theta^{d *}=\theta^{d R *}$, we can get $\frac{(u-b c) g}{4 b \eta-g^{2}}=\frac{R_{s} g}{\delta \eta}$, and then $R_{s}=\frac{(u-b c) \delta \eta}{4 b \eta-g^{2}}$. Considering $R_{s}<R_{s}^{d^{\prime}}$ together, we find that given $\frac{(u-b c) \delta \eta}{4 b \eta-g^{2}} \leq R_{s}<R_{s}^{d^{\prime}}$, there is $\theta^{d *}<\theta^{d R *}$; given $R_{s}<\frac{(u-b c) \delta \eta}{4 b \eta-g^{2}}$, there is $\theta^{d *}>\theta^{d R *}$.

c) The difference between the risk-neutral retailer's optimal expected profit and the risk-averse retailer's optimal expected profit is as follows:

$\Delta E\left(\pi_{r}^{d *}\right)=E\left(\pi_{r}^{d *}\right)-E\left(\pi_{r}^{d R *}\right)=\frac{b \eta^{2}(u-b c)^{2}}{\left(4 b \eta-g^{2}\right)^{2}}-\frac{(u-b c) \delta \eta-\left(b \eta-g^{2}\right) R_{s}}{\delta^{2} \eta} R_{r}+\frac{b}{\delta^{2}}\left(R_{r}\right)^{2}$

Let $\Delta E\left(\pi_{r}^{d *}\right)=0$, we find the following:

$R_{r}^{d t}=\frac{(u-b c) \delta \eta-\left(b \eta-g^{2}\right) R_{s}}{2 b \eta}-\sqrt{\left(\frac{(u-b c) \delta \eta-\left(b \eta-g^{2}\right) R_{s}}{2 b \eta}\right)^{2}-\frac{\delta^{2} \eta^{2}(u-b c)^{2}}{\left(4 b \eta-g^{2}\right)^{2}}}$

Then, given $0<R_{r}<R_{r}^{d t}$, there is $\Delta E\left(\pi_{r}^{d *}\right)>0$, i.e., $E\left(\pi_{r}^{d *}\right)>E\left(\pi_{r}^{d R *}\right)$; given $R_{r}^{d t} \leq R_{r}<R_{r}^{d}$, there is $\Delta E\left(\pi_{r}^{d *}\right) \leq 0$, i.e., $E\left(\pi_{r}^{d *}\right) \leq E\left(\pi_{r}^{d R *}\right)$. d) The difference between the risk-neutral supplier's optimal expected profit 
and the risk-averse supplier's optimal expected profit is as follows:

$\Delta E\left(\pi_{s}^{d *}\right)=E\left(\pi_{s}^{d *}\right)-E\left(\pi_{s}^{d R *}\right)=\frac{\eta(u-b c)^{2}}{2\left(4 b \eta-g^{2}\right)}-R_{s} \frac{(u-b c) \delta-b R_{r}}{\delta^{2}}+\left(R_{s}\right)^{2} \frac{2 b \eta-g^{2}}{2 \eta \delta^{2}}$

Then, we discuss as follows: first, given $\frac{(u-b c) \delta}{b}$ $\left(1-\sqrt{\frac{2 b \eta-g^{2}}{4 b \eta-g^{2}}}\right)<R_{r}<R_{r}^{d^{\prime}}, \quad$ there is always $E\left(\pi_{s}^{d *}\right)>E\left(\pi_{s}^{d R *}\right)$. S e c o n d , g i v e n $R_{r} \leq \frac{(u-b c) \delta}{b}\left(1-\sqrt{\frac{2 b \eta-g^{2}}{4 b \eta-g^{2}}}\right)$, we find that when $R_{s}^{d t} \leq R_{s}<R_{s}^{d^{\prime}}$, there is $\Delta E\left(\pi_{s}^{d *}\right) \leq 0$, i.e., $E\left(\pi_{s}^{d *}\right) \leq E\left(\pi_{s}^{d R *}\right)$; when $0<R_{s}<R_{s}^{d t}$, there is $\Delta E\left(\pi_{s}^{d *}\right)>0$, i.e., $E\left(\pi_{s}^{d *}\right)>E\left(\pi_{s}^{d R *}\right)$

Here, $R_{s}^{d t}=\frac{\eta}{2 b n-g^{2}}\left\{(u-b c) \delta-b R_{r}-\sqrt{\left((u-b c) \delta-b R_{r}\right)^{2}-\frac{\delta^{2}\left(u-b c^{2}\left(2 b b-g^{2}\right)\right.}{4 b b_{n}-g^{2}}}\right\}$

Proof of Corollary 5

The difference between the risk-neutral GSC's optimal expected profit and the risk-averse GSC's optimal expected profit is as follows:

$$
\begin{aligned}
\Delta E\left(\pi_{t}\right)=E\left(\pi_{t}^{d *}\right)-E\left(\pi_{t}^{d R *}\right) & =\frac{\eta\left(6 b \eta-g^{2}\right)(u-b c)^{2}}{2\left(4 b \eta-g^{2}\right)^{2}}-\frac{R_{r}(u-b c)}{\delta}+\frac{b\left(R_{r}\right)^{2}}{\delta^{2}} \\
& +R_{s} \frac{\left(2 b \eta-g^{2}\right) R_{r}-(u-b c) \delta \eta}{\delta^{2} \eta}+\left(R_{s}\right)^{2} \frac{2 b \eta-g^{2}}{2 \delta^{2} \eta}
\end{aligned}
$$

Then, we discuss as follows: first, given $R_{r}^{d h}<R_{r}<R_{r}^{d}$, there is always $E\left(\pi_{t}^{d *}\right)<E\left(\pi^{d R *}\right)$. Second, given $R_{r} \leq R_{r}^{d h}$, we find that when $R_{s}^{d h} \leq R_{s}<R_{s}^{d^{\prime}}$, there is $\Delta E\left(\pi_{t}\right) \leq 0$, i.e., $E\left(\pi_{t}^{d *}\right) \leq E\left(\pi_{t}^{d R *}\right)$; when $0<R_{s}<R_{s}^{d h}$, there is $\Delta E\left(\pi_{t}\right)>0$, $\mathrm{i} . \mathrm{e} ., \quad E\left(\pi_{+}^{d *}\right)>E\left(\pi_{+}^{d R *}\right)$. Here, $\quad R_{r}^{d h}=\frac{(u-b c) \delta \eta\left[\left(4 b \eta-g^{2}\right)-\sqrt{\left(2 b \eta-g^{2}\right)\left(5 b \eta-g^{2}\right)}\right]}{2 b \eta\left(4 b \eta-g^{2}\right)} \quad$ and $R_{s}^{d h}=\frac{(u-b c) \delta \eta-\left(2 b \eta-g^{2}\right) R_{r}-\sqrt{\frac{4(u-b c)^{2}(b b)^{2} \delta^{2} \eta^{2}}{\left.()^{2}-g^{2}-g^{2}\right)^{2}\left(2 b \eta-g^{2}\right)\left(R_{r}\right)^{2}}}}{2 b \eta-g^{2}}$

\section{Proof of Corollary 6}

a) It is obvious that $\theta^{d *}<\theta_{t}^{*}$. At the same time, because $\theta^{d R *}=\frac{R_{s} g}{\delta \eta}$ and $\theta_{t}^{R *}=\frac{g R_{t}}{\delta \eta}$, we can obtain $\theta^{d R *}<\theta_{t}^{R *}$.

b) Because $p^{d *}-p_{t}^{*}=\frac{\eta(u-b c)\left(2 b \eta-2 g^{2}\right)}{\left(4 b \eta-g^{2}\right)\left(2 b \eta-g^{2}\right)}>0$, we can o b tain $p_{t}^{*}<p^{d *} \cdot \quad$ Similarly, because $p^{d R *}-p_{t}^{R *}=\frac{\left(R_{s}+R_{r}-R\right)}{\delta}=0$, we can get $p_{t}^{R *}=p^{d R *}$.

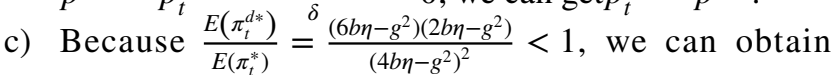
$E\left(\pi_{*}^{d *}\right)<E\left(\pi_{t}^{*}\right)$. Si milarly, because $\frac{E\left(\pi_{t *}^{d t^{*}}\right)}{E\left(\pi_{t}^{R *}\right)}=\frac{\left(4 b \eta-g^{2}\right)\left(2 b \eta-g^{2}\right)}{\left(3 b \eta-g^{2}\right)^{2}}<1$, we can easily find $E\left(\pi_{t}^{d R *}\right)<E\left(\pi_{t}^{R *}\right)$.

d) Because $R^{d^{\prime}}=R_{r}^{d^{\prime}}+R_{s}^{d^{\prime}}=\frac{2(u-b c) \delta \eta}{3 b \eta-g^{2}}$ and $R^{\prime}=\frac{(u-b c) \delta \eta}{2 b \eta-g^{2}}$, we can deduce $\frac{R^{d^{\prime}}}{R^{\prime}}=\frac{4 b \eta-2 g^{2}}{3 b \eta-g^{2}}>1$. Therefore, $R^{d}>R$.

\section{Proof of Proposition 3}

Taking the second-order partial derivative of $E\left(\pi_{r}^{s}\right)$ with respect to $p$, we have the following: $\frac{\partial^{2} E\left(\pi_{r}^{s}\right)}{\partial p^{2}}=-2 \lambda b<0$

Therefore, $E\left(\pi_{r}^{s}\right)$ is concave in $p$, and the retailer's optimal retail price is as follows:

$p^{s *}(\theta)=\frac{u+g \theta}{2 b}+\frac{w}{2 \lambda}$

Substitute $p^{s *}(\theta)$ into Eq. (13), then take the second order partial derivative of $E\left(\pi_{s}^{s}\right)$ with respect to $\theta$, and we have $\frac{\partial E^{2}\left(\pi_{s}^{s}\right)}{\partial \theta^{2}}=(1-\lambda) \frac{g^{2}}{2 b}-(1-\phi) \eta$.

When $\frac{1-\phi}{1-\lambda}>\frac{g^{2}}{2 b \eta}$ holds, $\frac{\partial E^{2}\left(\pi_{s}^{s}\right)}{\partial \theta^{2}}<0$. Then, $E\left(\pi_{s}^{s}\right)$ is concave in $\theta$, and we can get the following:

$\theta^{s *}=\frac{u g(1-\lambda)+b g(w-c)}{2 b(1-\phi) \eta-(1-\lambda) g^{2}}$

Substitute $\theta^{s *}$ into the expression of $p^{s *}(\theta)$ and we can have the following:

$p^{s *}=\frac{2(1-\phi) \eta u+g^{2}(w-c)}{2\left[2 b \eta(1-\phi)-(1-\lambda) g^{2}\right]}+\frac{w}{2 \lambda}$

The coordination conditions of risk-neutral decentralized GSC are $\theta_{t}^{*}=\theta^{s *}$ and $p_{t}^{*}=p^{s *}$. Then, it is easy to obtain $\lambda=\phi$ and $w=c \phi=c \lambda$.

Therefore, when $\frac{1-\phi}{1-\lambda}>\frac{g^{2}}{2 b \eta}, \lambda=\phi$, and $w=\phi c$ hold together, the RCS joint contract can coordinate the riskneutral GSC.

\section{Proof of Corollary 7}

Substituting $\theta_{t}^{*}$ and $p_{t}^{*}$ into the supplier's expected profit function in Eq. (13) and the retailer's expected profit function in Eq. (10), we have the following:

$E\left(\pi_{s}^{* *}\right)=(1-\phi) E\left(\pi_{t}^{*}\right)=(1-\lambda) E\left(\pi_{t}^{*}\right)$

$E\left(\pi_{r}^{s *}\right)=\phi E\left(\pi_{t}^{*}\right)=\lambda E\left(\pi_{t}^{*}\right)$

The conditions of Pareto improvement are $E\left(\pi_{s}^{s *}\right)$ $\geq E\left(\pi_{s}^{d *}\right)$ and $E\left(\pi_{r}^{s *}\right) \geq E\left(\pi_{r}^{d *}\right)$. Then, the inequation $E\left(\pi_{s}^{s *}\right) \geq E\left(\pi_{s}^{d *}\right) \quad$ can be expressed as $(1-\phi) E\left(\pi_{t}^{*}\right) \geq E\left(\pi_{s}^{d *}\right)$ or $(1-\lambda) E\left(\pi_{t}^{*}\right) \geq E\left(\pi_{s}^{d *}\right)$; the inequation $E\left(\pi_{r}^{s *}\right) \geq E\left(\pi_{r}^{d *}\right)$ can be expressed as $\phi E\left(\pi_{t}^{*}\right) \geq E\left(\pi_{r}^{d *}\right)$ or $\lambda E\left(\pi_{t}^{*}\right) \geq E\left(\pi_{r}^{d *}\right)$. Therefore, we can get $\frac{2 b \eta\left(2 b \eta-g^{2}\right)}{\left(4 b \eta-g^{2}\right)^{2}} \leq \phi \leq \frac{2 b \eta}{4 b \eta-g^{2}}$ or $\frac{2 b \eta\left(2 b \eta-g^{2}\right)}{\left(4 b \eta-g^{2}\right)^{2}} \leq \lambda \leq \frac{2 b \eta}{4 b \eta-g^{2}}$.

\section{Proof of Proposition 4}

$E\left(\pi_{r}^{s}\right)$ is concave in $p$ and the constraint $\sqrt{\operatorname{Var}\left(\pi_{r}^{s}\right)} \leq R_{r}$ is convex; we conclude that the optimization problem (11) is a convex optimization problem, whose optimal solution can be derived by KKT conditions. Then, we can construct the Lagrange function as follows. 
$L_{r}^{\mathrm{s}}\left(p, r_{3}\right)=E\left(\pi_{r}^{s}\right)+r_{3}\left(R_{r}-\sqrt{\operatorname{Var}\left(\pi_{r}^{s}\right)}\right)$

From the first-order KKT condition, we can get the following:

$p^{\mathrm{s} R *}=\frac{w \delta+R_{r}}{\lambda \delta}, r_{3}=\frac{\lambda u \delta-b w \delta-2 b R_{r}+\lambda \delta g \theta}{\lambda \delta^{2}}$

Substitute $p^{s R *}$ into the supplier's expected profit, then then take the second-order partial derivatives of $E\left(\pi_{s}^{s}\right)$ with respect to $w$ and $\theta$, and we have the Hessian matrix in the following.

$H=\left(\begin{array}{ll}\frac{\partial^{2} E\left(\pi_{s}^{s}\right)}{\partial \theta^{2}} & \frac{\partial E^{2}\left(\pi_{s}^{s}\right)}{\partial \theta \partial w} \\ \frac{\partial E^{2}\left(\pi_{s}^{s}\right)}{\partial w \partial \theta} & \frac{\partial^{2} E\left(\pi_{s}^{s}\right)}{\partial w^{2}}\end{array}\right)=\left(\begin{array}{cc}-\eta(1-\phi) & \frac{g}{\lambda} \\ \frac{g}{\lambda} & \frac{-2 b}{\lambda^{2}}\end{array}\right)$

When $2 b \eta(1-\phi)-g^{2}>0$, then $|H|=\frac{2 b \eta(1-\phi)-g^{2}}{\lambda^{2}}>0$. Because $\frac{\partial^{2} E\left(\pi_{s}^{s}\right)}{\partial \theta^{2}}<0$ and $\frac{\partial^{2} E\left(\pi_{s}^{s}\right)}{\partial w^{2}}<0$, we find that the Hessian $H$ is a negative definite. $E\left(\pi_{s}^{s}\right)$ is jointly concave in $w$ and $\theta$. Meanwhile, the constraint $\sqrt{\operatorname{Var}\left(\pi_{s}^{s}\right)} \leq R_{s}$ is convex. Therefore, we conclude that the optimization problem (14) is a convex optimization problem, whose optimal solution can be derived by KKT conditions. Then, we can construct the Lagrange function as follows.

$L_{s}^{s}\left(w, \theta, r_{4}\right)=E\left(\pi_{s}^{s}\right)+r_{4}\left(R_{s}-\sqrt{\operatorname{Var}\left(\pi_{s}^{s}\right)}\right)$

From the first-order KKT condition, we can get the following:

$w^{s R *}=\frac{\lambda\left(R_{s}+c \delta\right)+(\lambda-1) R_{r}}{\delta}, \theta^{s R *}=\frac{R_{s} g}{\delta(1-\phi) \eta}$$$
\mathrm{T}
$$$$
\mathrm{h}
$$

$p^{s R *}=\frac{c \delta+R_{s}+R_{r}}{\delta}, r_{3}=\frac{\lambda R_{s} g^{2}+\eta(1-\phi)\left[\lambda \delta u-b \lambda\left(c \delta+R_{s}+R_{r}\right)-b R_{r}\right]}{\delta^{2}(1-\phi) \eta \lambda}$, and $r_{4}=\frac{R_{s} g^{2}+\eta(1-\phi)\left[u \delta-b\left(c \delta+2 R_{s}+R_{r}\right)\right]}{\delta^{2}(1-\phi) \eta} \quad . \quad \mathrm{H}$ e $\mathrm{r}$ e , $\phi<1+\frac{\lambda R_{s} g^{2}}{\eta\left[\lambda \delta u-b \lambda\left(c \delta+R_{s}+R_{r}\right)-b R_{r}\right]}$ and $\phi<1-\frac{R_{s} g^{2}}{\eta\left[u \delta-b\left(c \delta+2 R_{s}+R_{r}\right)\right]}$ must hold.

According to the above equilibrium solutions, we then obtain the following:

$$
\begin{aligned}
& E\left(\pi_{s}^{s R *}\right)=\frac{R_{s}\left[g^{2} R_{s}-2 b \eta(1-\phi)\left(c \delta+R_{r}+R_{s}\right)+2 u \eta \delta(1-\phi)\right]}{2 \eta(1-\phi) \delta^{2}}>E\left(\pi_{s}^{d R *}\right) \\
& E\left(\pi_{r}^{s R *}\right)=\frac{R_{s} g^{2}\left[2(1-\phi) R_{r}-\phi R_{s}\right]+2 \eta(1-\phi)^{2} R_{r}\left[\delta u-b\left(c \delta+R_{r}+R_{s}\right)\right]}{2 \eta(1-\phi)^{2} \delta^{2}}
\end{aligned}
$$

Because.

$$
\begin{aligned}
\Delta E\left(\pi_{r}^{R}\right)= & E\left(\pi_{r}^{s R *}\right)-E\left(\pi_{r}^{d R *}\right) \\
& =\frac{R_{s} g^{2}\left[2(1-\phi) R_{r}-\phi R_{s}\right]+2 \eta(1-\phi)^{2} R_{r}\left[\delta u-b\left(c \delta+R_{r}+R_{s}\right)\right]}{2 \eta(1-\phi)^{2} \delta^{2}} \\
& -\frac{R_{r}}{\delta}\left[u-b c-\frac{b\left(R_{r}+R_{s}\right)}{\delta}+\frac{R_{s} g^{2}}{\delta \eta}\right]=\frac{\phi g^{2} R_{s}\left[2(1-\phi) R_{r}-R_{s}\right]}{2 \eta(1-\phi)^{2} \delta^{2}}
\end{aligned}
$$

We can easily find that, in the region $\phi \in\left(0, \max \left\{0,1-\frac{R_{s}}{2 R_{r}}\right\}\right] \cap\left(0, \min \left\{1+\frac{R_{g^{2}}}{\eta\left[u \delta-b\left(s \delta+2 R_{s}+R_{r}\right)\right]}, 1+\frac{\lambda R_{g^{2}}{ }^{2}}{\eta\left[\hat{\delta} \delta u-b \lambda\left(c \delta+R_{s}+R_{r}\right)-b R_{r}\right]}\right\}\right)$, there is $\Delta E\left(\pi_{r}^{R}\right) \geq 0$, i.e., $E\left(\pi_{r}^{s R *}\right) \geq E\left(\pi_{r}^{R *}\right)$. Based on the above discussion, we conclude that given $\phi \in\left(0, \max \left\{0,1-\frac{R_{s}}{2 R_{r}}\right\}\right]$ $\cap\left(0, \min \left\{1+\frac{R_{s} g^{2}}{\eta\left[u \delta-b\left(c \delta+2 R_{s}+R_{r}\right)\right]}, 1+\frac{\lambda R_{s} g^{2}}{\eta\left[\hat{\lambda} \delta u-b \lambda\left(c \delta+R_{s}+R_{r}\right)-b R_{r}\right]}\right\}\right)$, both members' expected profits are improved by the contract.

In total, the RCS joint contract is efficient in improving the performance of both the risk-neutral GSC and the riskaverse GSC.

Author contribution The mathematical model and suggested solution approaches were developed by Professor J. Cai. Then the model and solution approach were analyzed by H. Lin and X. Hu under the supervision of Professor J. Cai. The grammatical corrections were done by Professor J. Cai and M. Ping.

Funding This research is supported by National Natural Science Foundation of China $(71972171,71572184)$ and Natural Science Foundation of Zhejiang Province (LQ22G020012, LY19G020011).

Data availability Not applicable.

\section{Declarations}

Ethics approval Not applicable.

Consent to participate Not applicable.

Consent for publication All authors declare that there are consent for publication in the journal of Environmental Science and Pollution Research.

Conflict of interest The authors declare no competing interests.

\section{References}

Bai Q, Xu J, Chauhan SS (2020) Effects of sustainability investment and risk aversion on a two-stage supply chain coordination under a carbon tax policy. Comput Ind Eng 142:106324

Basiri Z, Heydari J (2017) A mathematical model for green supply chain coordination with substitutable products. J Clean Prod 145:232-249

Cai J, Hu X, Chen K, Tadikamalla PR, Shang J (2019) Supply chain coordination under production yield loss and downside risk aversion. Comput Ind Eng 127:353-365 
Chen MH, Wei H, Wei M, Huang H, Su CH (2021) Modeling a green supply chain in the hotel industry: an evolutionary game theory approach. Int J Hosp Manag 92:102716

Chiu CH, Choi TM (2016) Supply chain risk analysis with meanvariance models: a technical review. Ann Oper Res 240:489-507

Choi TM, Li D, Yan H, Chiu CH (2008) Channel coordination in supply chains with agents having mean-variance objectives. Omega 36:565-576

Choi TM, Wen X, Sun X, Chung SH (2019) The mean-variance approach for global supply chain risk analysis with air logistics in the blockchain technology era. Transp Res Part E Logist Transp Rev 127:178-191

Fan Y, Feng Y, Shou Y (2020) A risk-averse and buyer-led supply chain under option contract: CVaR minimization and channel coordination. Int J Prod Econ 219:66-81

Ghosh D, Shah J (2015) Supply chain analysis under green sensitive consumer demand and cost sharing contract. Int J Prod Econ 164:319-329

Ghosh D, Shah J (2012) A comparative analysis of greening policies across supply chain structures. Int J Prod Econ 135:568-583

Heydari J, Govindan K, Aslani A (2019) Pricing and greening decisions in a three-tier dual channel supply chain. Int $\mathrm{J}$ Prod Econ 217:185-196

Hong Z, Guo X (2019) Green product supply chain contracts considering environmental responsibilities. Omega 83:155-166

Huang Y, Wang K, Zhang T, Pang C (2016) Green supply chain coordination with greenhouse gases emissions management: a gametheoretic approach. J Clean Prod 112:2004-2014

Kellner R, Rösch D (2016) Quantifying market risk with value-at-risk or expected shortfall? - Consequences for capital requirements and model risk. J Econ Dyn Contro 1 68:45-63

Li B, Hou PW, Chen P, Li QH (2016a) Pricing strategy and coordination in a dual channel supply chain with a risk-averse retailer. Int J Prod Econ 178:154-168

Li B, Zhu M, Jiang Y, Li Z (2016b) Pricing policies of a competitive dual-channel green supply chain. J Clean Prod 112:2029-2042

Li G, Wu H, Sethi SP, Zhang X (2021) Contracting green product supply chains considering marketing efforts in the circular economy era. Int J Prod Econ 234:108041

Liu K, Li W, Cao E, Lan Y (2021) A behaviour-based pricing model of the green product supply chain. Environ Sci Pollut R. https:// doi.org/10.1007/s11356-021-15659-8

Li P, Rao C, Goh M, Yang Z (2021) Pricing strategies and profit coordination under a double echelon green supply chain. J Clean Prod 278:123694

Liu M, Cao E, Salifou CK (2016) Pricing strategies of a dual-channel supply chain with risk aversion. Transp Res Part E Logist Transp Rev 90:108-120

Liu P (2019) Pricing policies and coordination of low-carbon supply chain considering targeted advertisement and carbon emission reduction costs in the big data environment. J Clean Prod 210:343-357

Liu Z, Hua S, Zhai X (2020) Supply chain coordination with risk-averse retailer and option contract: supplier-led vs. retailer-led. Int J Prod Econ 223:107518

Markowitz H (1952) Portfolio selection. J. Finance 7:77-91
Qu S, Zhou Y, Zhang Y, Wahab MIM, Zhang G, Ye Y (2019) Optimal strategy for a green supply chain considering shipping policy and default risk. Comput Ind Eng 131:172-186

Raza SA, Govindaluri SM (2019) Pricing strategies in a dual-channel green supply chain with cannibalization and risk aversion. Oper Res Perspect 6:100118

Song H, Gao X (2018) Green supply chain game model and analysis under revenue-sharing contract. J Clean Prod 170:183-192

Swami S, Shah J (2013) Channel coordination in green supply chain management. J Oper Res Soc 64:336-351

Taleizadeh AA, Alizadeh-Basban N, Sarker BR (2018) Coordinated contracts in a two-echelon green supply chain considering pricing strategy. Comput Ind Eng 124:249-275

Tapiero CS (2005) Value at risk and inventory control. Eur J Oper Res 163:769-775

Wang S, Watada J, Pedrycz W (2009) Value-at-risk-based two-stage fuzzy facility location problems. IEEE Trans Ind Informatics 5:465-482

Wang W, Zhang Y, Zhang W, Gao G, Zhang H (2021) Incentive mechanisms in a green supply chain under demand uncertainty. J Clean Prod 279:123636

Wei Y, Choi TM (2010) Mean-variance analysis of supply chains under wholesale pricing and profit sharing schemes. Eur J Oper Res 204:255-262

Xiao T, Yang D (2009) Risk sharing and information revelation mechanism of a one-manufacturer and one-retailer supply chain facing an integrated competitor. Eur J Oper Res 196:1076-1085

Xie G, Yue W, Wang S, Lai KK (2011) Quality investment and price decision in a risk-averse supply chain. Eur J Oper Res 214:403-410

Xu G, Dan B, Zhang X, Liu C (2014) Coordinating a dual-channel supply chain with risk-averse under a two-way revenue sharing contract. Int J Prod Econ 147:171-179

Xu X, He P, Xu H, Zhang Q (2017) Supply chain coordination with green technology under cap-and-trade regulation. Int J Prod Econ 183:433-442

Yang H, Zhuo W, Shao L, Talluri S (2021) Mean-variance analysis of wholesale price contracts with a capital-constrained retailer: trade credit financing vs. bank credit financing. Eur J Oper Res 294:525-542

Yang L, Cai G, Chen J (2018) Push, pull, and supply chain risk-averse attitude. Prod Oper Manag 27:1534-1552

Yao Z, Xu X, Luan J (2016) Impact of the downside risk of retailer on the supply chain coordination. Comput Ind Eng 102:340-350

Zhao H, Song S, Zhang Y, Liao Y, Yue F (2020) Optimal decisions in supply chains with a call option contract under the carbon emissions tax regulation. J Clean Prod 271:122199

Zhu B, Wen B, Ji S, Qiu R (2020) Coordinating a dual-channel supply chain with conditional value-at-risk under uncertainties of yield and demand. Comput Ind Eng 139:106181

Zhu W, He Y (2017) Green product design in supply chains under competition. Eur J Oper Res 258:165-180

Zhuo W, Shao L, Yang H (2018) Mean-variance analysis of option contracts in a two-echelon supply chain. Eur J Oper Res 271:535-547

Publisher's note Springer Nature remains neutral with regard to jurisdictional claims in published maps and institutional affiliations. 